\title{
On the Use of Surface Plasmon Resonance-Based Biosensors for Advanced Bioprocess Monitoring
}

\author{
Jimmy Gaudreault ${ }^{1}$, Catherine Forest-Nault ${ }^{1,2}$, Gregory De Crescenzo ${ }^{1}$, Yves Durocher ${ }^{2,3}$ a and Olivier Henry ${ }^{1, *}$ \\ 1 Department of Chemical Engineering, Polytechnique Montreal, Montreal, QC H3T 1J4, Canada; \\ jimmy.gaudreault@polymtl.ca (J.G.); catherine.forest-nault@polymtl.ca (C.F.-N.); \\ gregory.decrescenzo@polymtl.ca (G.D.C.) \\ 2 Human Health Therapeutics Research Centre, National Research Council of Canada, Montreal, QC H4P 2R2, \\ Canada; yves.durocher@cnrc-nrc.gc.ca \\ 3 Department of Biochemistry and Molecular Medicine, University of Montreal, Montreal, QC H3T 1J4, Canada \\ * Correspondence: olivier.henry@polymtl.ca
}

Citation: Gaudreault, J.;

Forest-Nault, C.; De Crescenzo, G.;

Durocher, Y.; Henry, O. On the Use of Surface Plasmon Resonance-Based Biosensors for Advanced Bioprocess Monitoring. Processes 2021, 9, 1996. https://doi.org/10.3390/pr9111996

Academic Editors: Ralf Pörtner and Johannes Möller

Received: 18 October 2021

Accepted: 2 November 2021

Published: 9 November 2021

Publisher's Note: MDPI stays neutral with regard to jurisdictional claims in published maps and institutional affiliations.

Copyright: (c) 2021 by the authors. Licensee MDPI, Basel, Switzerland. This article is an open access article distributed under the terms and conditions of the Creative Commons Attribution (CC BY) license (https:/ / creativecommons.org/licenses/by/ $4.0 /)$.

\begin{abstract}
Biomanufacturers are being incited by regulatory agencies to transition from a quality by testing framework, where they extensively test their product after their production, to more of a quality by design or even quality by control framework. This requires powerful analytical tools and sensors enabling measurements of key process variables and/or product quality attributes during production, preferably in an online manner. As such, the demand for monitoring technologies is rapidly growing. In this context, we believe surface plasmon resonance (SPR)-based biosensors can play a role in enabling the development of improved bioprocess monitoring and control strategies. The SPR technique has been profusely used to probe the binding behavior of a solution species with a sensor surface-immobilized partner in an investigative context, but its ability to detect binding in real-time and without a label has been exploited for monitoring purposes and is promising for the near future. In this review, we examine applications of SPR that are or could be related to bioprocess monitoring in three spheres: biotherapeutics production monitoring, vaccine monitoring, and bacteria and contaminant detection. These applications mainly exploit SPR's ability to measure solution species concentrations, but performing kinetic analyses is also possible and could prove useful for product quality assessments. We follow with a discussion on the limitations of SPR in a monitoring role and how recent advances in hardware and SPR response modeling could counter them. Mainly, throughput limitations can be addressed by multi-detection spot instruments, and nonspecific binding effects can be alleviated by new antifouling materials. A plethora of methods are available for cell growth and metabolism monitoring, but product monitoring is performed mainly a posteriori. SPR-based biosensors exhibit potential as product monitoring tools from early production to the end of downstream processing, paving the way for more efficient production control. However, more work needs to be done to facilitate or eliminate the need for sample preprocessing and to optimize the experimental protocols.
\end{abstract}

Keywords: surface plasmon resonance (SPR); bioprocess; monitoring; biosensor; quality by design $(\mathrm{QbD})$; process analytical technology (PAT); biotherapeutics production; vaccines production

\section{Introduction}

Biomanufacturers are subject to strict directives imposed by regulatory agencies, such as the Food and Drug Administration (FDA) in the United States and the European Medicine Agency (EMA) in Europe, to ensure their products are fit to the highest standards of quality, efficacy, and safety. The biotherapeutic market of today is rapidly growing and evolving, with notable contributions attributed to the rise of therapeutic monoclonal antibodies [1] and expiring patents allowing the creation of more and more biosimilars [2].

Amid increasing demands, biomanufacturers aim to increase throughputs while retaining the quality and safety of their products. Products are typically extensively tested 
after production with fixed process parameters in what is commonly called a quality by testing framework. During the 2000s, the FDA introduced the concept of Quality by Design $(\mathrm{QbD})$ to guide quality control [3]. QbD aims to build quality within the product at the design stage rather than test it after its production. To accomplish that, the critical quality attributes (CQA) of a product must be identified to construct a quality target product profile (QTPP), which links CQAs to the critical process parameters (CPP). Such relations can be known a priori or investigated using concepts of design of experiments and a statistical analysis. Ensuring repeatability by aiming to maintain CQAs constant from batch to batch, rather than the process parameters, enables more process flexibility $[4,5]$. Doing so requires a thorough understanding of which attributes of a biotherapeutic are critical to its efficacy and safety and of their dependency on the process variables. Risk assessment and continuous improvement are also key concepts of $\mathrm{QbD}$ [6]. Knowing the link between CQAs and CPPs, quality by control $(\mathrm{QbC})$ becomes possible by manipulating $\mathrm{CPPs}$ to regulate CQAs. $\mathrm{QbC}$ necessitates measuring various process variables during production that are either CQAs themselves or that allow the prediction of CQAs via predictive modeling techniques $[7,8]$.

Process analytical technology (PAT) is another initiative from the FDA from the middle of the 2000s [9]. PAT encompasses the development of sensors allowing monitoring and process control methods taking advantage of the measurements provided by these sensors [10]. Techniques and devices aiming to measure the critical process variables linked to CQAs in a timely manner compared to the process dynamics are very much a part of the PAT framework [11]. As such, there is now a vast interest in techniques allowing process variable measurements online or at-line of the production vessel. Such tools enable the monitoring of bioprocesses either during upstream or downstream processing. Techniques that allow the monitoring of cell growth or cell metabolism may not be sufficient to perform $\mathrm{QbC}$, introducing a need for sensors allowing measurements on the product itself. Such sensors would not only be useful for production at the industrial scale but also during process development, when multiple conditions need to be tested. More efficient process development leads to a lower time to market, which is highly beneficial. To this day, adoption of the PAT framework is much more prominent at the R\&D stage than it is at the production stage, but we believe powerful new tools and ingenious data analysis methods could change that in the future. Figure 1 illustrates how real-time quality assessment tools can lead to a greater production efficiency by allowing decision-making during the production rather than a posteriori. Such process analytical technologies would enable the implementation of a quality by control framework in which production issues may be solved in real time by adjusting the production parameters. This would lead to a greater efficiency by ensuring more production batches are of acceptable quality. In this mindset, this review investigates the potential of surface plasmon resonance (SPR)-based biosensors as a monitoring tool that will allow real-time quality assessments and/or quantitation.

The surface plasmon resonance phenomenon was established by the pioneering work of Otto, Kretschmann and Raether in the late 1960s [12-14]. It was first commercialized in the form of a biosensor capable of detecting interactions between an immobilized species and its solubilized binding partner by Pharmacia (subsequently Biacore, now commercialized by Cytiva, formerly GE Healthcare) in the 1990s. Advances in the liquid handling and control systems have greatly improved the precision and sensitivity of SPR-based biosensors in the last three decades [15-21]. On top of this, robust protocols [22] and data analysis works [23-31] have helped establish SPR as a premiere technique in the field of biomolecule interaction analyses. Its main advantage lies in its ability to detect interactions without a label, which simplifies the assay design. As the interaction depends on a biological event between the immobilized and solubilized species, the technique only detects bioactive compounds rather than all compounds harboring a given label. Another significant benefit of SPR is its ability to track the interaction in real time. This enables a kinetic analysis of the interaction on top of affinity measurements [15]. A concentration analysis is also possible [32-35], and as such, SPR represents an interesting alternative to enzyme-linked 
immunosorbent assays (ELISA) for quantitation purposes [36]. SPR technology has been used in multiple fields, such as drug screening [16-18,21]; drug potency assessments [37]; vaccine quantitation [38-42]; food safety (the detection of bacteria, pathogens, and other impurities) [43-50]; biotherapeutics characterization and quality control [51-57]; biotherapeutic safety [58]; medical diagnostics [20,59-63]; environmental monitoring [64]; and bioproduction monitoring [55,65-68]. Although little work has been done for the aim of using an SPR biosensor online or at-line from a bioreactor in an automatic fashion $[67,68]$, a growing body of works showing accurate concentration measurements in complex media such as cell lysate $[55,65,67,68]$ and human serum [69] on top of advancements in antifouling technologies $[70,71]$ pave the way for using surface plasmon resonance-based biosensors in a bioprocess monitoring framework.

A

\section{Conventional Product Quality Assesment}
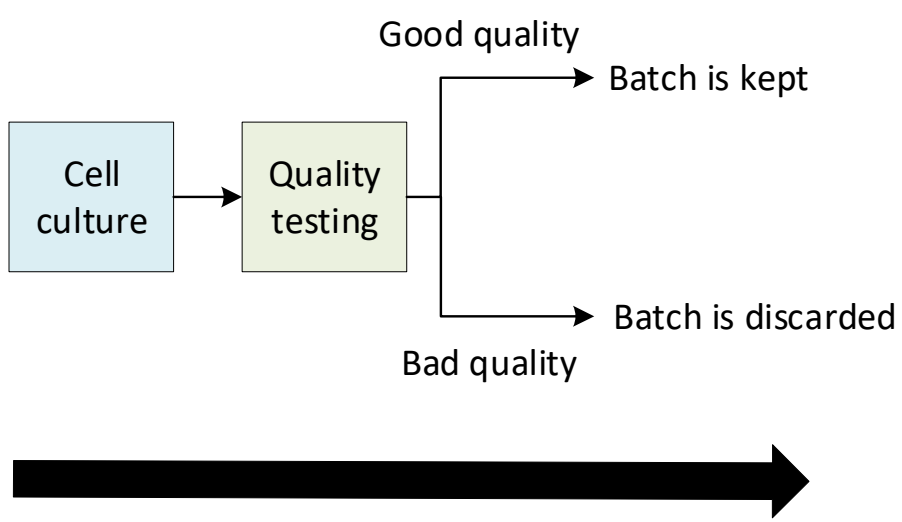

Time
B

\section{Quality Assesment}

Real-Time Product

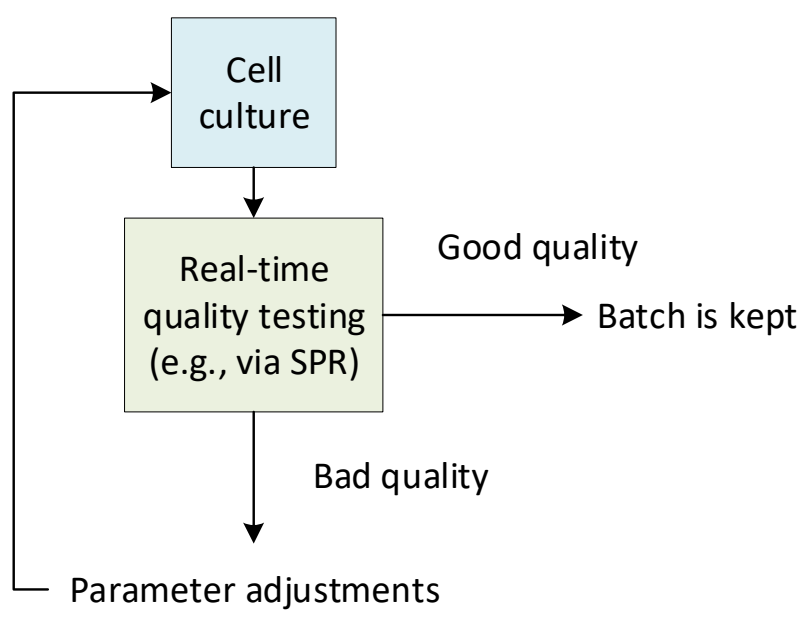

Figure 1. Conceptual differences between a conventional a posteriori quality assessment (A) and real-time quality assessment (B) of a cell culture-derived product. The conventional framework allows the detection of production issues only after the cell culture is finished, which may cause significant losses if a production batch is found to be inadequate and needs to be discarded. On the other hand, in a real-time quality assessment framework, a batch can be preemptively stopped if production problems start being detected during the cell culture. Eventually, a quality by control framework becomes possible, where one adjusts the production parameters to solve quality problems during the production. This can help discard fewer batches and, thus, greatly increase the efficiency.

First, the SPR phenomenon will be presented with the main considerations for a robust SPR assay, as well as general directions for kinetic and concentration analyses using SPR. The applications of SPR in monitoring biotherapeutics, vaccine antigens, viral particles, and bacteria will then be presented with some details on the assay designs found in the literature. The limitations of SPR in a monitoring context will emerge from this literature review, and they will be discussed next. We will then examine the recent biosensor and modeling headways. These are mainly aimed at increasing the throughput or treating more complex samples. Some compelling developments have not yet been applied to monitoring but could prove powerful tools in the near future. We will conclude with some perspectives on which key technological advancements are necessary to establish SPR as a predominant monitoring tool in the future. 


\section{Surface Plasmon Resonance: Basic Principles and Methods}

Surface plasmon resonance-based biosensors rely on the excitation of an electron cloud, called a plasmon, at the interface between a noble metal-typically gold-and a dielectric medium following the projection of a polarized monochromatic light on the metal. This results in the propagation of an evanescent wave. When the near-infrared incident light projected by a laser hits the metal surface such that the component of the incident wave light that is parallel to the surface $\left(k_{x}\right)$ perfectly aligns with the surface plasmon waves $\left(k_{s p}\right)$, the oscillations of the surface plasmon are amplified; hence, there is resonance. A glass prism is typically used to ensure the total internal reflection of the light (see Figure 2A). This corresponds to the geometry suggested by Kretschmann and Raether $[12,13]$. Therefore, when resonance occurs, energy that would otherwise be used in reflecting the light instead goes to amplifying the oscillations of the electrons, resulting in a drop in the reflected light intensity, which can be measured in real time. The light incident angle for which resonance occurs, called the SPR angle, depends on the refractive index of the dielectric media in the evanescent wave propagation zone. As the refractive index depends on the concentration of material near the surface, SPR can be used to track the accumulation of proteins at the surface in real time by rapidly changing the incident angle of the projected light and monitoring the changes in the SPR angle.

Some SPR biosensors vary the wavelength of the incident light and use a spectrophotometer as a detector. It is also possible to keep the angle and wavelength constant while monitoring the intensity shift. This technique facilitates measurements at multiple detection spots simultaneously using SPR imaging instruments (SPRi; see Section 7). However, configurations that directly measure the SPR angle or wavelength are preferred, as the intensity shift is only a derivative measurement of the SPR angle/wavelength, which are linked more directly to the quantity of accumulated material near the surface [72]. Shifts in the phase of the light when SPR occurs can also be monitored. Such setups have not been broadly commercialized, as they require complex instrumentation, but they allow better sensitivity as the phase shift of the light is more abrupt than the variations of its intensity $[73,74]$ (see Section 7). For more details on the SPR phenomenon and SPR biosensor configurations, the reader is referred to various reviews on SPR biosensing [15-21,74]. A non-exhaustive list of SPR instrument manufacturers is given in Table 1.

SPR biosensors allow real-time and label-free measurements of the interaction between a ligand immobilized on a biosensor metallic surface and an analyte introduced near the surface, for example, via a microfluidic channel. The biological interaction between the analyte and the ligand results in the accumulation of analytes near the biosensor, causing a change in the refractive index and SPR angle (see Figure 2B), which can be monitored to obtain a SPR sensorgram (see Figure 2C).

Ligand immobilization can be performed via multiple chemical approaches by using readily available SPR sensor chips with a tethered carboxymethylated dextran layer, as offered by Cytiva [15]. Oriented strategies are preferred when available, as they minimize the heterogeneity in the ligand interaction and steric hindrance, resulting in sensorgrams that are simpler to analyze.

Following ligand immobilization, multiple SPR cycles can be performed on the same sensor surface. A SPR cycle, or sensorgram, can be separated into three main phases (Figure 2D): first, a buffer injection phase (to obtain a baseline signal), an analyte injection phase during which analyte-ligand complexes are formed (association phase), and a second buffer injection phase to dissociate analyte-ligand complexes (dissociation phase). The association and dissociation durations, injection flow rate, and temperature can be set by the user for most high-grade SPR biosensors. The SPR signal is measured in RU (resonance units), with $1 \mathrm{RU}$ being roughly equivalent to $1 \mathrm{pg} / \mathrm{mm}^{2}$ of immobilized protein [75]. 
A
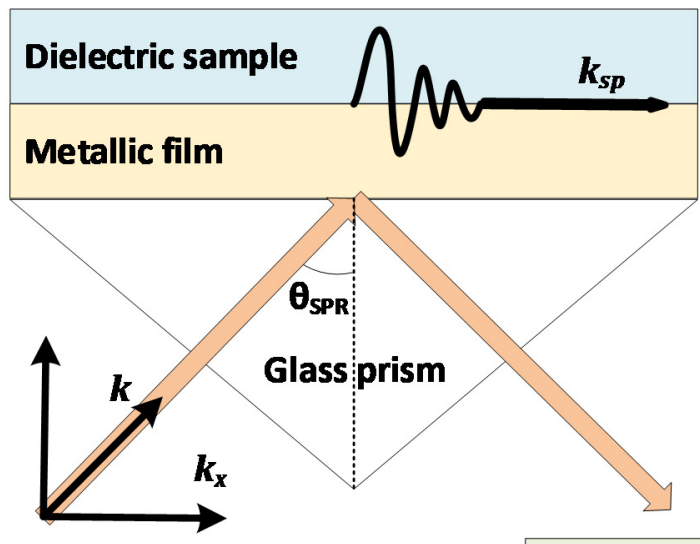

Polarized

Monochromatic Light
B

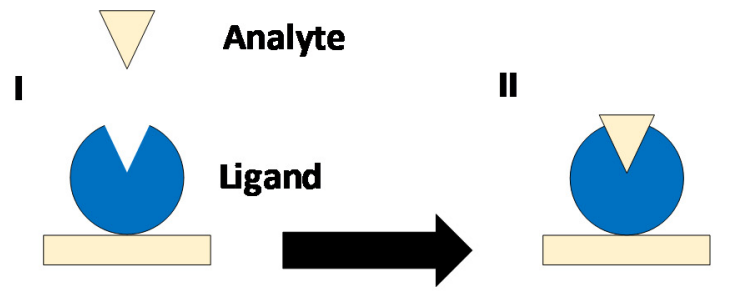

Analyte diffusion towards the surface

$+$

Analyte-ligand binding

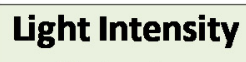

Detector

c

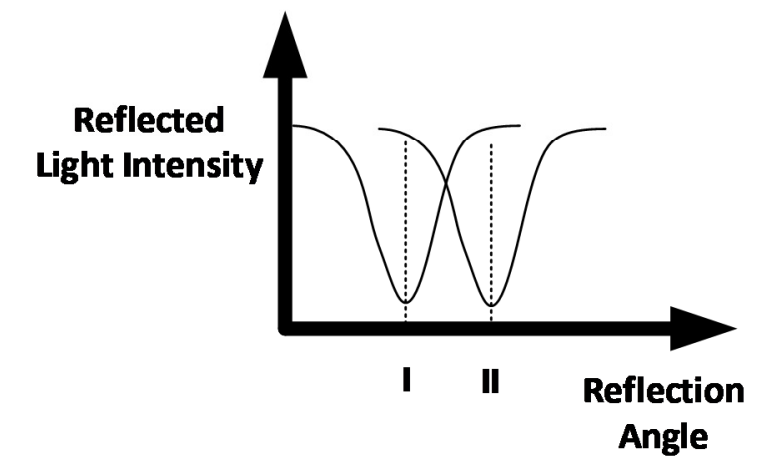
SPR Sensorgram
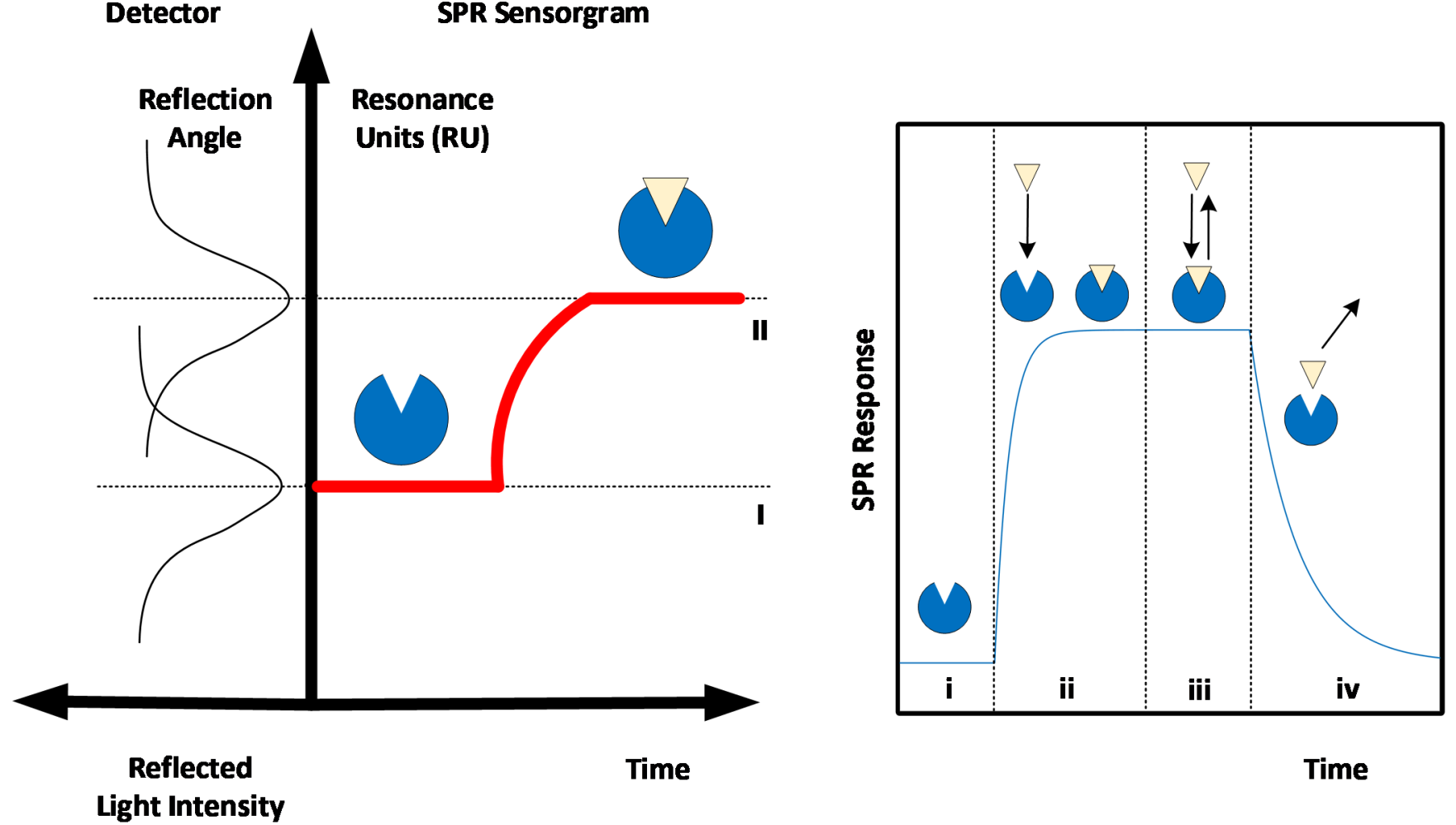

Figure 2. Surface plasmon resonance (SPR)-based biosensing principle. (A) Kretschmann-Raether biosensor configuration. Projecting near-infrared light at a specific angle (SPR angle) results in accrued oscillations of electron clouds (plasmon) at the interface between a dielectric sample and a metallic surface, hence the resonance of the surface plasmon. (B) Accumulation of materials (analyte molecules) on the metallic SPR surface creates a change in the SPR angle. (C) The change in the SPR angle can be monitored in real time to obtain a SPR sensorgram. (D) Phases of a SPR sensorgram: (i) baseline, (ii) association phase, (iii) equilibrium, and (iv) dissociation phase. 
Table 1. Surface plasmon resonance biosensor manufacturers. SPR instruments can either vary the angle of the incident light or its wavelength. Some manufacturers utilize variations on the traditional SPR technique to increase the throughput or to increase the applicability to complex samples.

\begin{tabular}{cccc}
\hline Manufacturer & SPR Method & Detection & Reference \\
\hline Affinité Instruments & SPR & Wavelength & {$[76]$} \\
\hline Biacore (Cytiva) & SPR & Angle & {$[77]$} \\
\hline Bionavis & Multi Parametric SPR (MP-SPR) & Angle & {$[78]$} \\
\hline Biosensing Instrument & SPR & Angle & {$[79]$} \\
\hline Carterra & SPR Imaging (SPRi) & Angle & {$[80]$} \\
\hline Reichert Technologies & SPR & Angle & {$[81]$} \\
\hline Sierra Sensors (Bruker) & SPR Imaging (SPRi) & Angle & {$[82]$} \\
\hline
\end{tabular}

To obtain repeatable signals, it is essential that the amount of available, biologically active ligand molecules remains constant from one sensorgram to the other. In order to ensure this, all analyte molecules should be removed from the surface by the end of the dissociation phase. For slowly dissociating systems, a regeneration step may be necessary during which a harder solution (typically in terms of $\mathrm{pH}$ or salt concentration) is injected. Selecting an appropriate regeneration solution may be challenging, as regeneration needs to remove all analyte molecules without removing or damaging the ligand molecules $[15,83,84]$.

SPR sensorgrams can be biased by nonspecific interactions between the analyte or other components of the injected sample and the SPR surface. Signal artefacts can also be observed (caused by sharp refractive index variations when switching from one buffer to another, by electric perturbations due to the biosensor's moving parts, etc.). As such, a robust experimental protocol includes a second SPR surface (mock) to perform a reference. The mock surface is exposed to the same sequence of injections as the active surface, except that it does not harbor any ligand molecules. Thus, subtracting the signal recorded on the reference surface from the signal recorded on the active surface removes nonspecific contributions. A second reference may be performed by repeating the same sequence of injections with a null concentration of the analyte or a blank (i.e., injecting buffer instead of the analyte). This removes signal drifts, which can occur when the temperature near the SPR surface is not constant during the experiment, as the refractive index also depends on the temperature. Sensorgrams obtained by subtracting the reference surface signal and the referenced blank injection signal are said to be double-referenced [22].

The following subsections will describe the two main uses of SPR: analyzing the kinetic and equilibrium behaviors of an analyte-ligand interaction and quantifying the solution of an analyte. Although the latter can perhaps seem more appropriate for bioprocess monitoring purposes, one should also strive to monitor the critical quality attributes (CQAs) of the product, which may influence the binding kinetics to its biological partners. As an example, monoclonal antibody (mAb) $\mathrm{N}$-glycosylation (a CQA of mAbs) is known to influence IgG-Fc $\gamma R$ binding kinetics, as measured by SPR, and, hence, the efficacy and safety of therapeutic mAbs [51].

\subsection{SPR to Measure Kinetics and Affinity}

As SPR biosensors allow real-time measurements, the kinetics of an analyte-ligand interaction can be measured. A typical kinetic SPR assay includes multiple cycles with distinct known analyte concentrations, from which the rate constants are extracted by globally fitting an interaction model to multiple double-referenced sensorgrams via optimization methods [15].

The simplest and most commonly used interaction model, called a 1:1 Langmuir model, contains an association rate $k_{a}[=] \mathrm{M}^{-1} s^{-1}$ and a dissociation rate $k_{d}[=] \mathrm{s}^{-1}$, which mediate a reversible pseudo-reaction between a free analyte molecule $A$ and an immo- 
bilized ligand molecule $L$ to form an analyte-ligand complex $A L[15,25]$. Both kinetic constants have an impact during the association phase, whereas only $k_{d}$ influences the signal during the dissociation phase. For the model to be appropriate, the predicted signal (with fitted model parameters) should adequately describe the recorded signal. This can be validated by observing that the residues (differences between fitted and measured signals) are randomly distributed with a null mean $[23,25]$. An inadequate fit to an ideal 1:1 Langmuir model can typically be explained either by a poor SPR assay design or by the presence of a more complex interaction scheme. Such complexity can hail from the presence of heterogeneity in the system (either in the analyte [26,28-31] or the ligand [85-88] molecules), the stoichiometry of the analyte-ligand interaction [89-92], or a conformational change following analyte-ligand binding $[93,94]$. Forest-Nault et al. [51] provided a description of the modeling approaches that can be used to analyze such complexities in SPR data and offered insight on the modeling of IgG-Fc $\gamma$ receptor $(\mathrm{Fc} \gamma \mathrm{R})$ interactions, which has long been studied using SPR and for which nonideal behaviors have repeatedly been observed and confirmed.

The system may reach an equilibrium state during the association phase, for which the binding and dissociation of the analyte-ligand complex occur at the same rate. Such an equilibrium is detected by the appearance of a plateau in the SPR signal. In the Langmuir model, the value of this plateau is characterized by the equilibrium constant $K_{D}=\frac{k_{d}}{k_{a}}[=] \mathrm{M}$ or by the affinity $K_{A}=\frac{k_{a}}{k_{d}}[=] \mathrm{M}^{-1}$. Interestingly, many complex models behave similarly to the ideal model at equilibrium, enabling thermodynamic measurements even if the kinetics are not properly understood.

\subsection{SPR to Measure Concentrations}

Kinetic analyses, like those described in the previous section, are typically performed in conditions for which the analyte-ligand interactions are limited by the interaction kinetics. This is achieved by performing experiments with a relatively low density of immobilized ligands and a high flow rate. Conversely, the conditions of mass transport limitations enable the quantitation of bioactive analytes. Indeed, when using a SPR surface that is highly concentrated in ligand molecules and a low flow rate, the diffusion of the analyte molecules from the bulk solution toward the SPR surface is the limiting step in the analyte-ligand binding process. This is characterized by a linear signal during the association phase of the sensorgrams, with the slope of the signal being proportional to the analyte concentration of the injected solution [34,35]. Interestingly, SPR has been used to estimate analyte concentrations in a multitude of sample media [33], including cell culture broths $[55,65,67,68]$ and human serum [69]. Examples of applications of quantitation via calibration will be discussed in the following sections for different relevant types of analytes.

Analyte concentrations can be measured either with or without calibration, depending on the availability of an analyte solution of a known concentration. The calibration refers to the construction of a standard graph of the initial slope of the SPR signal with respect to the analyte concentration. Under conditions of mass transport limitations, such a graph should be linear, with a null initial value [32,34], although a four-parameter logistic function has also been used $[65,95]$, allowing a broader applicability, since the linearity range may be limited. Rather than the slope, some authors used the SPR signal obtained at the end of a set analyte injection time as the measurement, which may have a broader applicability outside the linearity range $[58,65,66,69]$.

The CFCA method (for calibration-free concentration analysis) requires estimating the mass transport kinetic constant $k_{M}[=] \frac{\mathrm{m}}{\mathrm{s}}$. Briefly, $k_{M}$ is a function of the dimensions of the microfluidic channel, the diffusion coefficient of the analyte in the buffer, and the cubic root of the injection flow rate. An estimate equation of $k_{M}$ has long been available [34,96,97], but its use remains complex, mainly due to the need to estimate the diffusion coefficient. This can be done using the Einstein-Sutherland equation, which is based on Stoke's law, but it requires knowledge of the relative frictional ratio and the solvent viscosity [32]. The 
molar weight of the analyte is also necessary to convert $k_{M}$ from units of concentration to RU [32,34]. To determine the analyte concentration via CFCA, conditions of at least partial mass transport limitations are necessary, and the analyte sample must be injected at two different flow rates, meaning two different $k_{M}$ values [35]. For details of the CFCA procedure, and a description of the acceptable degree of mass transport limitation, the reader is referred to a relevant review on CFCA [33].

Uncertainties of the value of the analyte diffusion coefficient and the molar weight may bias the computation of $k_{M}$ and, hence, the concentration estimated via CFCA. Comparing two samples to obtain the ratio of their respective concentration with CFCA may prove more efficient and accurate, as the uncertainties cancel each other when computing the ratio [32,33,37]. A reference sample-for example, a quality control-is then compared to a second sample on the basis of their bioactivity, as SPR only detects bioactive analyte molecules that can interact with the ligand. Matching the absorbance measurements at $280 \mathrm{~nm}$ normalizes the quantity of the proteins in both samples, enabling potency comparison [32]. Potency could be compared across different batches to ensure batch-tobatch variability in product folding. Potency could also be monitored before and after each purification step of a bioprocess to detect product denaturation caused by the purification process $[32,98]$ or before and after exposure to a stress such as heat or $\mathrm{pH}$ to quantify the product stability [33,37].

Relative CFCA was used in guiding the purification process of interferon $\alpha-2 \mathrm{a}[32,98]$ by helping select a chromatography resin and the purification conditions, which maximized the purified product bioactivity. Notably, by using a mouse anti-interferon $\alpha$ antibody as the ligand, a relative concentration (normalized via absorbance) above $100 \%$ was found between the samples before and after purification, indicating that purification indeed removed denatured products. CFCA was also used to evaluate the potency of TNF- $\alpha$ before and after temperature stress, proving an alternative to a traditional $\mathrm{EC}_{50}$ analysis [37]. Absolute CFCA was recently used to quantify human myoglobin with good agreement with isotope dilution mass spectrometry measurements [99], and a mathematical framework was developed to quantify analytes prone to self-association [100]. CFCA, especially in a relative framework, has already been proven to be efficient and accurate, and we predict its use will increase in the near future.

\section{SPR Applications to Biotherapeutics Production Monitoring}

Biotherapeutics are mainly produced by cultivating mammalian cells in a bioreactor. These bioprocesses can be sensitive to various operating parameters, such as $\mathrm{pH}$, temperature, culture media, feeding strategy, bioreactor operation mode, cell line, etc. [101]. These parameters may be dynamic, and the length of the culture may also influence the product quality. As such, there is an obvious interest for tools allowing monitoring during production. Surface plasmon resonance-based biosensors represent an interesting option in that regard, as they can be used to quantify the product (as a faster alternative to ELISA) and to probe binding to its biological partners, which can often be indicative of the product quality, efficacy, and/or safety. SPR has been used to analyze various types of molecules in this context, including antibodies [65-67,102], fusion proteins [57], peptides [68], complement fragments [58], and other blood proteins [66,103].

Table 2 summarizes the quantitation assays that will be described in this section. Although they mostly aim at quantifying antibodies, similar assays could be used to quantify any number of proteins, as long as an interacting partner (or an antibody) is available to play the role of the immobilized ligand. In addition to these, biotherapeutics quality assessment probes will also be discussed. They come in the form of either a kinetic analysis or a qualitative yes/no binding experiment. 
Table 2. Quantitation assays of the biotherapeutics reported in this section. The concentration ranges used to build a calibration curve are also reported.

\begin{tabular}{|c|c|c|c|c|}
\hline Target Analyte & Ligand & $\begin{array}{l}\text { Range } \\
(\mu \mathrm{g} / \mathrm{mL})\end{array}$ & SPR Instrument & Reference \\
\hline $\mathrm{mAb}$ & Antibody & $0.8-50$ & \multirow{9}{*}{ Biacore T200 } & \multirow{9}{*}{ [66] } \\
\hline Albumin & Antibody & $2-200$ & & \\
\hline Transferrin & Antibody & $0.2-20$ & & \\
\hline $\operatorname{Ig} \mathrm{A}$ & Antibody & $0.4-50$ & & \\
\hline $\operatorname{IgG}$ & Antibody & $2-200$ & & \\
\hline IgG1 & Antibody & $2.8-90$ & & \\
\hline $\operatorname{IgG} 2$ & Antibody & $1.8-60$ & & \\
\hline IgG3 & Antibody & $0.4-13$ & & \\
\hline IgG4 & Antibody & $0.2-5$ & & \\
\hline $\begin{array}{c}\text { Infliximab } \\
\text { (IFX, IgG mAb) }\end{array}$ & Antigen (TNF- $\alpha)$ & $0.5-8$ & \multirow[t]{2}{*}{ Bio-Rad ProteOn } & \multirow[t]{2}{*}{ [69] } \\
\hline Anti-IFX antibody & Antibody (IFX) & $5-40$ & & \\
\hline $\begin{array}{l}\text { Anti-GFP antibody } \\
\text { (total) }\end{array}$ & Protein A/G & $0.03-2$ & \multirow{2}{*}{$\begin{array}{c}\text { SPR 2/4 } \\
\text { (Bruker } \\
\text { Daltonics SPR) }\end{array}$} & \multirow{2}{*}[65]{} \\
\hline $\begin{array}{l}\text { Anti-GFP antibody } \\
\text { (bioactive) }\end{array}$ & Antigen (GFP) & $0.03-2$ & & \\
\hline Anti-PSMA IgG mAb & Antigen (PSMA) & $1.35-30$ & Biacore 3000 & [67] \\
\hline $\begin{array}{l}\text { Trastuzumab } \\
\text { (IgG mAb) }\end{array}$ & Fc $\gamma$ RI & $0.03-3.75$ & Biacore T100 & [55] \\
\hline Anti-TNF- $\alpha$ antibody & Antigen (TNF- $\alpha)$ & $0.02-360$ & Biacore T200 & [37] \\
\hline
\end{tabular}

\subsection{SPR for the Early Development of Biotherapeutics}

As the first SPR-based biosensors became available in the early 1990s, they were used to characterize biomolecule interactions and rapidly played an instrumental role in accelerating therapeutic antibody screening and epitope binning experiments [104]. In combination with technologies such as phage display, which enable the creation of large libraries of candidates based on bacteriophage expression, SPR helped identify candidates with the most therapeutic potential $[105,106]$. These strategies led to the rise of one of the

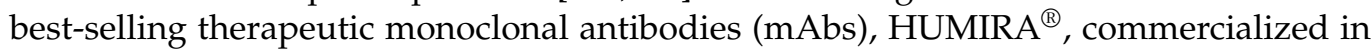
2003, and continue to be an essential part in discovery research for new therapeutics against cancer or diseases like hepatitis, HIV, and Alzheimer's [104,107,108]. Kinetic analyses performed by SPR not only allow discriminating between good candidates based on their target specificity but, also, to better understand and estimate the target occupancy and residence time of the therapy [109]. These parameters have become increasingly important in lead optimization in order to minimize off-target effects and ensure therapeutic efficacy by target engagement.

Several studies have described practical approaches based on SPR to study the offtarget binding of candidates by serum proteins. This can significantly influence their pharmacokinetic profile and propensity to induce side effects. Frostell et al. showed early on that it is possible to efficiently evaluate the binding of plasma proteins to drug candidates by immobilizing plasma proteins on an SPR surface. Their results correlated with other methods such as ELISA [110]. Gonzales et al. compared the immunogenicity of potential antibody variants against a protein, TAG-72, expressed by several kinds of carcinomas [111]. Ritter et al. used SPR to measure the antibody response in the serum of patients that were treated with humanized anti-A33, an antibody that targets colon cancer [112]. Today, therapeutic drug and immunogenicity monitoring (TDIM) is more and 
more implemented to guide therapy with biologics by taking into account personalized drug responses to make informed decisions on the course of treatment. Moreover, SPR was shown to be more cost-effective than ELISA for serum concentration analyses, as SPR protocols tend to be simpler and faster [69]. Therefore, with the advantages of low sample volume consumption and real-time and label-free analysis, SPR has rapidly become recognized as a powerful tool and has been extensively used for the early assessment of target specificity, binding stability, and expression levels, which is essential data for the selection of potential drugs [104].

As the market of biotherapeutics has grown over the years, the complexity of their path to commercialization pushed regulatory agencies and industrials to adapt the development workflow of drugs and add the evaluation of more developability aspects such as post-translational modifications, conformation, aggregation, solution stability, and pharmacokinetic properties upstream of the development to reduce the risk of failure downstream as much as possible [104]. The role of SPR also evolved to meet those new requirements, and novel approaches were developed to rapidly characterize and predict a variety of biotherapeutic attributes. For example, antibody clearance can be partly estimated by its interactions with the neonatal Fc receptor FcRn. In fact, FcRn is responsible for recycling antibodies captured in endosomes by binding to their Fc region and leading them back to the cell surface $[113,114]$. By studying the antibody-FcRn interactions with SPR, it is possible to identify characteristics or residues of the antibody that are favorable to recycling by FcRn and, thus, increase the antibody half-life [115]. Until recently, SPR-based biosensors and their applications were limited by their low throughput. Recent advances, which will be covered in Section 7, have unlocked the full potential of SPR monitoring at every stage of biotherapeutics development and even during production and purification by increasing the throughput.

\subsection{SPR for the Quantification of Biotherapeutics}

Therapeutic monoclonal antibodies represent a rapidly growing global market in the biopharmaceutical field estimated to reach USD $\$ 300$ billion by 2025 [1]. In a recently published study, two SPR assays were suggested to probe the total and bioactive $\mathrm{mAb}$ concentrations from a culture broth [65]. Protein A/G was used as the ligand to detect the total concentration, whereas the $\mathrm{mAb}$-specific antigen (here, green fluorescent protein (GFP)) was used to detect only the bioactive antibodies that are properly folded, such that they may play their biological role. Calibration was performed using samples of known concentrations. Various GFP immobilization strategies were compared, and a combination of His-tag capturing and amine coupling stood out for allowing the fast online quantitation of bioactive anti-GFP antibodies. His-tag capturing enables oriented immobilization, whereas amine coupling offers reusability of the sensor surface as the ligand molecules are covalently bound to the dextran layer of the sensor chip. A limit of detection of $1.8 \mathrm{ng} / \mathrm{mL}$ was achieved using the adapted immobilization method, which was shown to be similar to that of an ELISA procedure [65].

SPR has also shown to be a capable alternative to ELISA in quantifying proteins in diluted serum samples. Frostell et al. [66] developed SPR assays for the specific quantitation of eight plasma proteins (IgA, IgGs, albumin, and transferrin) and a recombinant $\mathrm{mAb}$ from samples taken during production in Chinese Hamster Ovary (CHO) cell cultures. Interestingly, these authors suggested not to perform any reference when conducting a concentration analysis, as they argue that an unmodified surface is not a representative negative control of the active surface when the latter contains large quantities of ligand molecules such as antibodies. They proposed to use a surface on which an irrelevant antibody is bound as a possible alternative but chose not to do so, as adequation to the active surface remained uncertain. The proposed SPR assays were shown to be robust, precise, and faster than an ELISA. In a notable recent study, Infliximab (IFX), a monoclonal antibody against TNF- $\alpha$, and antibodies against IFX were quantified in human serum samples [69]. In this study, calibration was performed by spiking the serum samples with 
known concentrations of analytes. Nonspecific contributions by serum proteins binding to the surface were referenced out by injecting the serum on a mock surface (for assays with TNF- $\alpha$ as the ligand to quantify IFX) or a surface harboring a set level of a nonspecific $\operatorname{IgG}$ (for assays with IFX as the ligand to quantify anti-IFX antibodies). The calibration and reference protocols used when treating complex media are particularly relevant to the field of bioprocess monitoring, and such studies show the potential of the SPR technique in treating complex matrices.

Harnessing a SPR biosensor to a bioreactor allowed at-line quantitation of the product during its production via cell culture $[67,68]$. A system of peristaltic pumps enabled automatic sampling at a fixed time interval, with automated dilution of the cell media. The only purification steps between the biosensor and the 3.5-L bioreactor were a decantation column and a filter, which removed cells and cellular debris that could clog the SPR microfluidic channels. The whole process was fully automated. Figure 3 shows a schematic of this experimental setup. The quantitation of anti-PSMA antibodies was performed by immobilizing PSMA (prostate-specific membrane antigen) on the sensor chip [67]. The concentrations measured at-line were in agreement with the concentrations measured offline with SPR and with quantitative Western blotting followed by densitometry analyses. Calibration was automatically repeated every $12 \mathrm{~h}$ using samples of known concentrations. More work needs to be done to render SPR biosensing more apt to the treatment of samples being automatically harvested, but these two studies showed an interesting proof of concept.

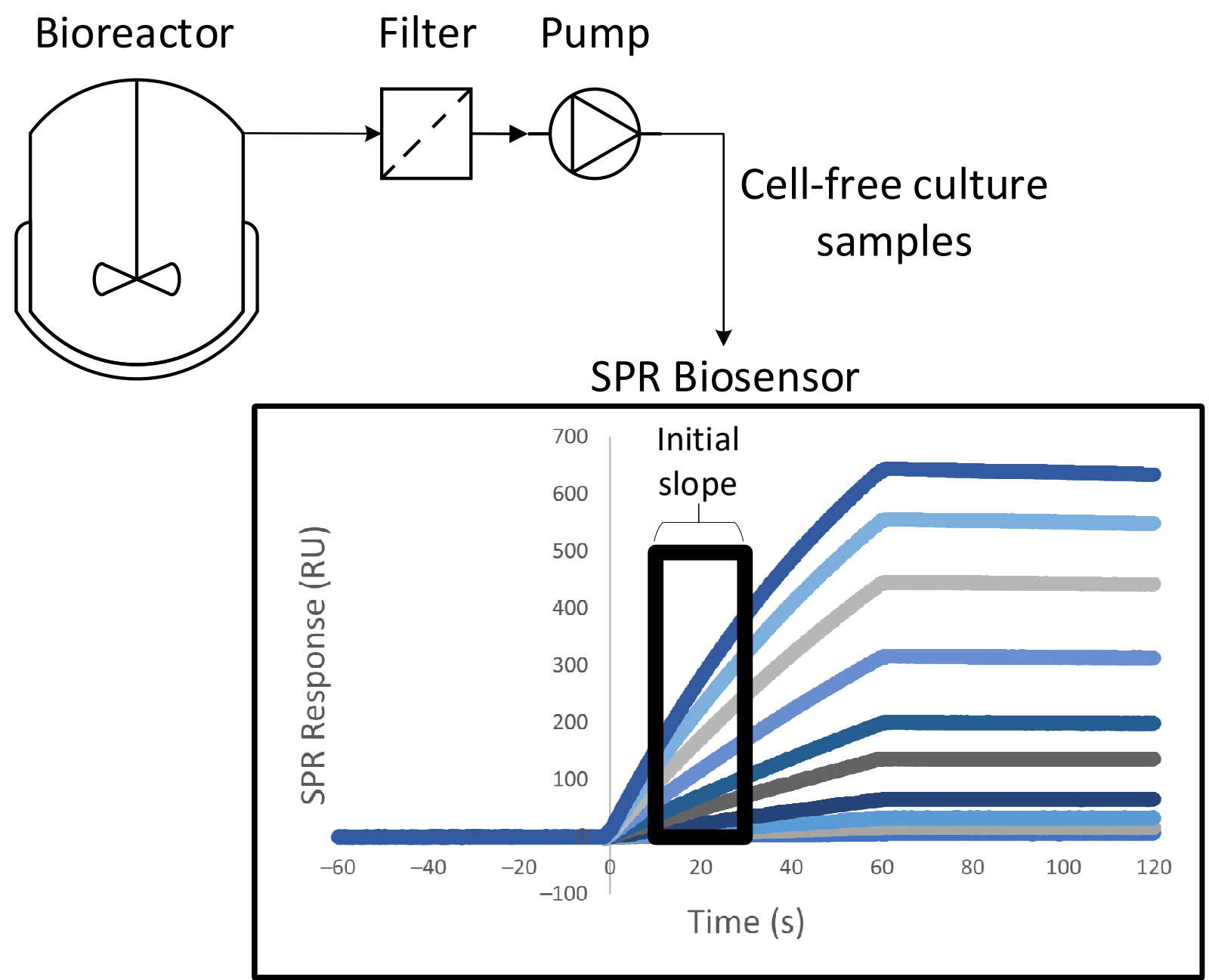

Figure 3. Schematic of the experimental setup suggested by Chavane et al. [67] for an at-line concentration analysis via SPR. 


\subsection{SPR for the Safety and Quality Assessment of Biotherapeutics}

Certain product safety probes can be performed with SPR. As an example, an SPR assay allowing the monitoring of complement activation by nanoparticles was recently detailed [58]. Complement activation is undesirable in this context, as it causes an inflammatory reaction aimed at eliminating the nanoparticles when they are administered intravenously as therapeutic agents. Emulsion-based nanoparticles were incubated in human serum before performing SPR experiments. A total of four SPR surfaces were used. The first one displayed a polyclonal antibody against $\mathrm{C} 3$ fragments, while the second contained a monoclonal antibody specific to $\mathrm{C} 3 \mathrm{a}$. Complement activation was detected if either one of these surfaces exhibited a non-null SPR response when injecting the serum samples. The remaining two were reference surfaces: one unmodified and one with an irrelevant antibody. The SPR results were similar to those obtained via immunoelectrophoresis, whereas an ELISA approach resulted in high nonspecific background noise. Removing the nanoparticles prior to the experiment biased the detection of $\mathrm{C} 3 \mathrm{a}$, as it seemed to adsorb on the surface of the nanoparticles, potentially leading to false negatives. C3a could be adequately detected when samples containing the nanoparticles were tested [58].

SPR has also been used to investigate post-translational modifications of proteins. Post-translational modifications may affect the efficacy and safety of biotherapeutics and can therefore be classified as critical quality attributes in a Quality by Design framework. Monoclonal antibody N-glycosylation has been studied abundantly with SPR, as it affects binding to immune system effector cells, by measuring the binding of differently glycosylated mAb samples either to Fc receptors [51-54] or to lectins [56]. In another study, phosphorylation (another post-translational modification) was investigated by immobilizing tumor suppressor P53 on a sensor surface. Kinases were then injected on the surface, causing P53 phosphorylation. As phosphorylation affects P53 binding to the murine double minute 2 (MDM2) protein, the injection of MDM2 enabled the probing of phosphorylation [103].

Most of the current methods to probe the protein quality are ill-suited for online utilization. In contrast, a monitoring tool such as a SPR biosensor could allow the product quality to be considered in the very early stages of bioprocess development, such that it becomes an integral part of the control strategy.

\subsection{Sequential SPR Assays}

Sequential SPR assays enable both the quantitation of antibodies and the measure of their binding kinetics with Fc receptors in a single sensorgram. A large concentration of antigens is immobilized on the sensor surface. The assay starts with the injection of the antibodies, which bind to the immobilized antigens via their Fab region, enabling quantitation by measuring the slope of the recorded signal. This is followed by an injection of Fc receptors, which bind the antigen-bound antibodies via their $\mathrm{Fc}_{\mathrm{c}}$ region. If the assay is well-calibrated, kinetic evaluation is possible with the recorded signal resulting from the Fc receptor injections. The sequence may be reversed if one aims to evaluate the antigen-binding kinetics. Such a sequential assay was used to quantify Trastuzumab in a culture supernatant by immobilizing Fc $\gamma$ receptors and then measuring its kinetics to its antigen (HER2) [55]. On the same note, biotinylated TNF- $\alpha$ was immobilized on a SPR surface, enabling the quantitation of an anti-TNF- $\alpha$ antibody. This was followed either by an injection of the TNF- $\alpha$ receptor to verify TNF- $\alpha$ blocking by the antibodies or by an injection of $F c \gamma R$ [37]. In another study, antibodies from crude hybridoma were captured on the SPR surface via an anti-Fc antibody, allowing their quantitation and subsequent antigen-binding kinetic evaluation via a second injection [102]. The first injection (quantitation) may be performed with species in a complex medium (cell lysate), whereas kinetic studies (second injection) are generally performed in a defined buffer for more accurate measurements. Sequential assays could prove a powerful tool for the introduction of SPR biosensors in bioprocess monitoring, as they alleviate the need for 
purification, multiple SPR surfaces, and regeneration steps by combining the quantitation and quality assessment probes.

\section{SPR Applications to Vaccine Production Monitoring}

Several research groups have investigated the potential of SPR-based biosensors in quantifying vaccine production. The gold standard in this field has long been the single radial immunodiffusion (SRID) assay, but it requires strain-specific reference antisera and corresponding antigens, which may take up to 6 months to obtain by sheep immunization [40]. ELISA-based assays can be used as robust alternatives, but they remain time-consuming. For this reason, there is a strong interest in methods capable of performing vaccine quantitation without a reference serum, which could supplement SRID to speed up vaccine development. Furthermore, the elaboration of better vaccine potency assays is promoted by regulatory agencies, such as the World Health Organization (WHO) [116].

SPR-based assays have proven to be an efficient alternative to SRID. Low hands-on time and the total analysis time ( 10 min for SPR versus 2 to 3 days for SRID [41]) are probably the two main advantages of the technique in a monitoring and/or development context, enabling the rapid measurements required for proper decision-making and control during production and/or purification. The small sample volume $(\sim 100 \mu \mathrm{L})$ required for the analysis is another notable advantage. Research groups have achieved low detection limits and appreciable quantitation ranges either by changing the assay format or by robust reference and ligand immobilization strategies, rendering monitoring possible from the early stages of production, be it in eggs or in a cell culture, to the end of the purification process. Proofs of concept for the use of SPR in virus quantification have mainly been performed on influenza, but other viruses have been studied with SPR in a diagnostic framework [20,59-61]. For all these reasons, we anticipate a growing role of SPR biosensors in vaccine manufacturing processes in the coming years.

Most research groups aim to quantify vaccine antigen levels [38-40,42,117], while others seek to estimate the viral particle concentration $[41,118]$. Other than that, vaccines can also be made of viral-like particles (VLPs). Briefly, VLPs are structures that mimic the conformation of viral particles but lack the viral genome [119]. VLPs can play a role as nanovaccines or drug nanocarriers [120]. The methods typically used to quantify VLPs are the same as those employed to quantify viruses. This complicates VLP production monitoring, as those methods are ill-suited to online or at-line measurements [121]. Adenoviruses have also recently been investigated as vaccine vehicles and can be quantified via SPR [122]. Table 3 summarizes the quantitation assays that will be discussed in this section.

Table 3. Quantitation assays of the vaccines or viral particles reported in this section. The concentrations used to build a calibration curve are also reported. The limit of quantitation (LOQ) and the limit of detection (LOD) are given when available. The limit of quantitation is the smallest concentration that can be precisely identified, whereas the limit of detection is the smallest concentration that can be qualitatively detected (yes/no detection).

\begin{tabular}{|c|c|c|c|c|c|c|}
\hline Target Analyte & Ligand & Range & LOQ & LOD & SPR Instrument & Reference \\
\hline $\begin{array}{l}\text { Strains of Influenza HA } \\
\text { and Vaccine HA }\end{array}$ & $\begin{array}{l}\text { Synthetic glycans with } \alpha-2,3 \text { or } \\
\alpha-2,6 \text { sialic acid conformation }\end{array}$ & $0.33-30 \mu \mathrm{g} / \mathrm{mL}$ & & & Bio-Rad ProteOn & [40] \\
\hline Strains of Influenza HA & $\begin{array}{l}\text { Biantennary glycan with } \\
\text { terminal } \alpha-2,6 \text { sialic acid }\end{array}$ & $0.01-2 \mu \mathrm{g} / \mathrm{mL}$ & $0.01-0.02 \mu \mathrm{g} / \mathrm{mL}$ & & Biacore T200 & [42] \\
\hline $\begin{array}{l}\text { HA from viral serum } \\
\text { and Vaccine HA }\end{array}$ & $\begin{array}{c}\text { Recombinant HA } \\
\text { (Inhibition assay with Anti-HA } \\
\text { antibody) }\end{array}$ & $1-15 \mu \mathrm{g} / \mathrm{mL}$ & $1 \mu \mathrm{g} / \mathrm{mL}$ & $0.5 \mu \mathrm{g} / \mathrm{mL}$ & Biacore T100 & [39] \\
\hline Adenovirus & $\begin{array}{c}\text { Antibody against } \\
\text { anti-adenovirus antibody } \\
\text { (Inhibition assay with } \\
\text { anti-adenovirus antibody) }\end{array}$ & 10-5000 PFU/mL & & $10 \mathrm{PFU} / \mathrm{mL}$ & $\begin{array}{c}\text { SPRI-Lab+ } \\
\text { (Horiba Scientific, } \\
\text { Edison, USA) }\end{array}$ & [118] \\
\hline Influenza HA & $\begin{array}{c}6^{\prime} \text {-sialyllactose-conjugate with } \\
\text { ovalbumin as carrier }\end{array}$ & $10-100 \mu \mathrm{g} / \mathrm{mL}$ & & & $\begin{array}{l}\text { Biacore } 2000 \& \\
\text { Biacore X }\end{array}$ & [38] \\
\hline Vaccine HA & \multirow{2}{*}{$\begin{array}{l}\text { Fetuin glycoprotein bearing } \\
\text { both } \alpha-2,3 \text { and } \alpha-2,6 \text { linkages }\end{array}$} & $0.03-20 \mu \mathrm{g} / \mathrm{mL}$ & $0.1 \mu \mathrm{g} / \mathrm{mL}$ & $0.03 \mu \mathrm{g} / \mathrm{mL}$ & \multirow[b]{2}{*}{$\begin{array}{l}\text { SPR-2 (Sierra } \\
\text { Sensors) }\end{array}$} & \multirow[b]{2}{*}{ [41] } \\
\hline $\begin{array}{l}\text { Cell culture-derived } \\
\text { whole influenza virus }\end{array}$ & & $\sim 10^{5}-10^{7} \mathrm{PFU} / \mathrm{mL}$ & $5.3 \times 10^{5} \mathrm{PFU} / \mathrm{mL}$ & $\begin{array}{l}1.8 \times 10^{5} \\
\mathrm{PFU} / \mathrm{mL}\end{array}$ & & \\
\hline
\end{tabular}




\subsection{SPR for Quantification of Vaccines Preparations}

The most used model system is the influenza virus, which can be detected via hemagglutinin (HA), a homotrimeric glycoprotein found on the membrane of the virus. As such, an HA binding partner is used as the immobilized ligand. For the selection of an appropriate ligand, aiming to replicate the infection process of influenza is a sound strategy. Infection occurs when sialic receptors on HA bind terminal sialic acid residues on cell surface glycoproteins [123,124]. Therefore, most research groups use sialic acids or conjugates containing a sialic acid moiety as the ligand. Lectins can also be used [38], as HA exhibits carbohydrate sites on its surface. Note that such SPR assays will detect viral particles whether they are infectious or not, as long as they display HA [41].

Influenza strains recognize sialic acid residues that are linked to galactose either in an $\alpha-2,3$ (avian strain) or $\alpha-2,6$ (human strain) conformation. Khurana and colleagues [40] used synthetic glycans containing either of these conformations to quantitate different strains of influenza HA and HA contents of the vaccine preparations of several manufacturers, showing excellent agreement with the SRID methods. The biotinylated ligands were immobilized on a biosensor surface with grafted NeutrAvidin, and regeneration was possible. Doses ranging from 0.33 to $30 \mu \mathrm{g}$ HA per $\mathrm{mL}$ were used for calibration purposes, and the initial slope of the signal was recorded. Biotinylated glycans were also used to study the kinetics and affinity of several influenza strains to multivalent glycans with either $\alpha-2,3$ or $\alpha-2,6$ linkage [117]. The ability to measure interaction kinetics is absent in most other virus detection methods, including SRID.

A SPR assay based on a biantennary glycan with terminal $\alpha-2,6$ sialic acid residues that strongly bind human influenza virus strain HAs from 1999 to 2017 was introduced by Bruce-Staskal and colleagues [42]. An asialoglycan was immobilized on the reference surface. As their SPR assay emulates a biologically relevant binding event, the authors argued it can distinguish between native and denatured HA conformations. The total binding levels recorded with their assay were impacted by stresses (temperature and $\mathrm{pH}$ ) applied to the sample. As such, the proposed SPR assay can indirectly measure degradation and/or unfolding and, hence, be used to assess the half-life and stability of a vaccine preparation [42].

An inhibition assay was suggested to increase the sensitivity of SPR-based methods [39]. An anti-HA antibody was added in excess to influenza vaccine preparations a sufficiently long time before the SPR experiment to allow the reaching of a steady state. At a steady state, the remaining free antibodies (which had not bound to any HA) were titrated with recombinant HA immobilized at the biosensor surface. One could correlate the recorded SPR signal to the solution concentration of viral particles [72]. Of interest, a lower concentration of viral particles meant more free antibodies in the solution available for binding on the SPR surface and, thus, a higher SPR response. This allowed for a lower detection limit. A quantitation range of $1-15 \mu \mathrm{g} / \mathrm{mL}$ (via calibration with samples of known concentrations) was achieved for three influenza strains with a detection limit of less than $0.5 \mu \mathrm{g} / \mathrm{L}$ (respectively, $10-30 \mu \mathrm{g} / \mathrm{mL}$ and $\sim 5 \mathrm{~g} / \mathrm{mL}$ for SRID, according to these authors) [39]. A similar assay was suggested for the detection of adenoviruses [118]. In that case, a detection range of 10-5000 PFU (plaque-forming units) per $\mathrm{mL}$ was achieved.

\subsection{SPR for Quantification of Vaccines during Production}

Mandenius and colleagues [38] probed four compounds containing a sialic acid moiety and three lectins as potential ligands for continuous HA quantification by SPR. Continuous immunosensing requires a low-affinity ligand with a high dissociation rate, so that a regeneration step is unnecessary. A rapidly dissociating analyte also reaches equilibrium rapidly during the association phase. By continuously injecting pulses of the culture medium on the weak-affinity ligand surface, the concentration can be monitored online by monitoring the equilibrium plateau values, which are a function of the analyte concentration [125]. The retained ligand was a $6^{\prime}$-sialyllactose conjugate with a substitution level of $0.6 \mathrm{~mol}$ of ligand per mole of carrier protein (ovalbumin). This ligand was shown to exhibit low 
affinity $(\sim \mu \mathrm{M})$ binding to HA samples coming from egg or cell-based productions with a rapid dissociation $\left(\sim \mathrm{s}^{-1}\right)$, which would theoretically enable a fast analysis in an online fashion. The other tested ligands bound HA too strongly for this purpose, possibly due to avidity effects. A reference surface containing only ovalbumin was shown to adequately replicate nonspecific contributions. Human serum albumin was rejected as a protein carrier, as it caused more prominent nonspecific contributions than ovalbumin in this system. These authors showed that SPR responses at equilibrium correlated to the concentration measurements obtained with an SRID assay [38].

Using different SPR surfaces to quantify different influenza strains is suboptimal, especially when analyzing multivalent vaccine preparation. As such, ligands bearing both $\alpha-2,3$ and $\alpha-2,6$ linkages, such as fetuin glycoproteins, are of particular interest. A fetuin-based SPR imaging (SPRi; see Section 7) assay was suggested, which offered a higher reproducibility and better quantitation range $(0.03-20 \mu \mathrm{g} / \mathrm{mL})$ than SRID [41]. The assay was tested on influenza vaccine antigens and egg- and cell culture-derived whole influenza viruses. Of interest, viral particle production based on a culture of Madin-Darby Canine Kidney cells (MDCK) was monitored at-line from 1 to 4 days post-infection. Only a 10-min clarification by slow centrifugation was performed between the culture vessel (T-175 flask) and the biosensor. Of interest, multiple culture media caused negligeable nonspecific binding when injected alone on the biosensing surface, which paved the way to the at-line monitoring of multiple cell lines. Amongst them, the EMEM medium was selected, as it is appropriate for MDCK cells. Truncated fetuin (without terminal sialic acids) was observed to be a more reliable control surface ligand than bovine serum albumin, as it exhibited a lower nonspecific binding to HA. For antigen quantitation, calibrations were performed on HA samples of known concentrations, and the initial binding rates were recorded. For viral particle quantitation, either an infectivity assay (PFU) or total particles counting (TRPS) were used as a surrogate assay for concentration determination. The SPR signal initial slope strongly correlated linearly to both measurements. However, plaque-forming units only depend on infectious particles, not total particles exhibiting HA, as does SPR. Infectious viral particles cannot be directly quantified using SPR [41]. The ability to monitor vaccine production at-line is certainly desirable. On top of that, SPR can efficiently supplement SRID even in an offline framework by providing rapid measurements that can help speed development and testing.

\section{SPR Applications in Bacteria and Contaminant Monitoring}

SPR assays developed in the field of food safety could be adapted to bioprocess monitoring to ensure product safety and detect contamination. Such assays aim to detect bacteria or other pathogens in enrichment broths, in liquids, or in food dilutions [43]. Correspondingly, detecting impurities in cell culture media or a purified product is of interest to ensure the safety of biotherapeutics [44]. Traditional methods for bacteria detection such as colony counting and culture-based techniques require several experimental steps. The same thing can be said of alternative techniques such as ELISA and polymerase chain reaction (PCR), making them lengthy and laborious [45]. The ease of use of SPR and the low analysis time could prove very useful in this field.

Bacteria detection is usually done by immobilizing a bacteria-specific antibody on the biosensing surface. Bacteriophages have also been used $[45,126,127]$. The sensitivity of direct SPR assays may prove limiting, with a typical lower detection limit of about $10^{5}$ colony-forming units (CFU) per milliliter. Here, sensitivity is quantified by the limit of detection, which is defined as the concentration of bacteria that causes an SPR response equivalent to the average value of the instrument noise (control) plus three times its standard deviation [46]. Table 4 summarizes the quantitation assays discussed in this section.

The sensitivity was improved by selecting an oriented ligand immobilization strategy, by taking advantage of the biotin-NeutrAvidin link to immobilize a biotinylated antibody, or by using protein A/G to capture the antibodies via their Fc region. A detection limit of $10^{2} \mathrm{CFU} / \mathrm{mL}$ was achieved [45]. 
The sensitivity can also be improved by performing a sandwich assay [47,48]. A sandwich assay requires a second antibody that recognizes a different binding site on the bacteria membrane. After injecting the bacteria on the immobilized antibodies, the second antibodies are injected. This amplifies the signal, making it so a lower concentration of bacteria produces a detectable SPR response [72]. The detection limit of Campylobacter jejuni was enhanced from $8 \times 10^{6} \mathrm{CFU} / \mathrm{mL}$ to $4 \times 10^{4} \mathrm{CFU} / \mathrm{mL}$ by switching from a direct to a sandwich scheme. This compared favorably to a commercial ELISA assay $\left(10^{6}-10^{7} \mathrm{CFU} / \mathrm{mL}\right)$ [48]. Bhandari and colleagues [47] suggested incubating the secondary antibody with the bacteria prior to injecting them both rather than injecting them sequentially. Their assay achieved a lower detection limit of Salmonella Typhimurium in romaine lettuce samples of $4.7 \times 10^{5} \mathrm{CFU} / \mathrm{mL}$, which proved more sensitive than the direct $\left(1.9 \times 10^{6} \mathrm{CFU} / \mathrm{mL}\right)$ and typical sandwich $\left(1.6 \times 10^{6} \mathrm{CFU} / \mathrm{mL}\right)$ assays [47].

Table 4. Quantitation assays of the bacteria reported in this section. The assay type and the limit of detection (LOD) are also given for each assay. Sandwich assays tend to exhibit a better sensitivity (lower LOD) than direct assays. A subtractive inhibition assay was reported with excellent sensitivity, because it requires detecting an antibody rather than the bacterium itself.

\begin{tabular}{|c|c|c|c|c|c|}
\hline Target Analyte & Ligand & Assay Type & $\begin{array}{c}\text { LOD } \\
(\mathrm{CFU} / \mathrm{mL})\end{array}$ & SPR Instrument & Reference \\
\hline \multirow{2}{*}{ Campylobacter jejuni } & \multirow{2}{*}{ Antibody } & Direct & $8 \times 10^{6}$ & \multirow{2}{*}{ SPR-4 (Sierra Sensors) } & \multirow{2}{*}{ [48] } \\
\hline & & Sandwich & $4 \times 10^{4}$ & & \\
\hline Campylobacter jejuni & Antibody & $\begin{array}{l}\text { Subtractive } \\
\text { inhibition }\end{array}$ & 131 & SPR-4 (Sierra Sensors) & [49] \\
\hline \multirow{3}{*}{$\begin{array}{l}\text { Salmonella Typhimurium in } \\
\text { romaine lettuce }\end{array}$} & \multirow{3}{*}{ Antibody } & Direct & $1.9 \times 10^{6}$ & \multirow{3}{*}{$\begin{array}{l}\text { Reichert Dual Channel } \\
\text { SR7500DC }\end{array}$} & \multirow{3}{*}{ [47] } \\
\hline & & Sandwich & $1.6 \times 10^{6}$ & & \\
\hline & & $\begin{array}{l}\text { Sandwich with } \\
\text { prior incubation }\end{array}$ & $4.7 \times 10^{5}$ & & \\
\hline $\begin{array}{c}\text { Escherichia coli } \mathrm{O} 157: \mathrm{H7} \text { in } \\
\text { ground beef and } \\
\text { cucumber samples }\end{array}$ & $\begin{array}{l}\text { Wheat germ } \\
\text { agglutinin (lectin) }\end{array}$ & Direct & $3 \times 10^{3}$ & Biacore 3000 & [46] \\
\hline $\begin{array}{l}\text { Listeria monocytogenes } \\
\text { in milk }\end{array}$ & $\begin{array}{l}\text { Wheat germ } \\
\text { agglutinin (lectin) }\end{array}$ & Direct & $10^{4}$ & Biacore 3000 & {$[50]$} \\
\hline Listeria monocytogenes & $\begin{array}{l}\text { Phage-displayed } \\
\text { single-chain antibody }\end{array}$ & Direct & $2 \times 10^{6}$ & $\begin{array}{l}\text { Nomadics SPR3 } \\
\text { (SPREETA3, Texas } \\
\text { Instruments) }\end{array}$ & [127] \\
\hline
\end{tabular}

Another explanation for the sensitivity issues is the insufficient depth of the evanescent wave (approximately $300 \mathrm{~nm}$ compared to the size of a bacterium, which is on the order of $1 \mu \mathrm{m})[45,128]$. Mass accumulation on the SPR surface has a decaying importance on the SPR signal with the distance from the metal surface [33]. As such, using smaller ligands could improve the sensitivity. Antibody Fab fragments or other small binders such as aptamers would be appropriate for this purpose. For more details, the reader is referred to a recent review on the use of aptamer-based biosensors to detect Pseudomonas aeruginosa [129]. This also signifies that, for a sandwich assay to amplify the signal, the second antibody must bind the bacteria near the metal surface; otherwise, they are not perceived $[48,130]$.

C. jejuni could be detected at a limit of $131 \mathrm{CFU} / \mathrm{mL}$ in chicken samples with a subtractive inhibition assay [49]. Briefly, the sample was incubated with an excess of antibodies. The concentration of the remaining free antibodies after incubation was dependent on the concentration of bacteria. These free antibodies were collected via centrifugation and injected on a SPR surface with an immobilized secondary antibody. As such, this method relied on the detection of an antibody, which was smaller than the penetration depth of the evanescent wave, rather than the bacteria themselves. This enabled a better sensitivity. 
Assays using lectins as the ligand were also suggested. Wheat germ agglutinin (WGA) has been used to detect Escherichia coli O157:H7 in ground beef and cucumber samples [46] and Listeria monocytogenes in milk [50]. Nonspecific binding may affect the sensitivity in food samples, as better detection limits were reported in the buffer. Researchers in this field verify the specificity of their methods by evaluating their cross-reactivity to other bacteria, but little seems to be done to reference the contributions from other components of food samples, such as fibers, vitamins, carbohydrates, etc. Advances in referencing strategies will need to be made to counter their effect on the recorded SPR signal.

Due to the limitations reported in this section, we conclude that the detection of microorganisms via SPR is challenging but feasible, especially with more sophisticated assays. Other limitations include the possibility of clogging the microfluidic channels of the biosensor and the very slow diffusion rate of the bacteria towards the surface [131]. Although some of the reported studies showed statistically significant differences in SPR responses for different bacteria concentrations, pointing towards quantitation, the main goal in this field remains the detection of a particular bacterium species while limiting false positives caused by cross-reactivity to other species.

\section{Limitations of SPR Biosensing in the Context of Bioprocess Monitoring}

We now describe the major hurdles in the application of SPR for bioprocess monitoring. In a monitoring context, assays enabling rapid measurements with limited or no human handling of the samples are strongly preferred. A kinetic SPR assay requires injecting the analyte solution at different concentrations, which implies the need for diluting samples. A concentration analysis requires either a calibration to be repeated periodically or injections of each sample at two different flow rates. However, the total analysis time remains competitive, as each cycle lasts approximately $10 \mathrm{~min}$, meaning a result in a matter of hours. This is still favorable over ELISA or SRID.

SPR sensor surfaces on which a ligand has been immobilized are reusable, but this often comes with the need for a regeneration step. Indeed, the available immobilized ligand molecule density must remain constant from one cycle to another. As such, all analyte molecules must be removed from the surface after each experiment by injecting a more 'aggressive' regeneration solution, increasing the cycle cost and duration. Selecting the proper regeneration solution can be one of the most challenging steps in designing an SPR assay. This is a major shortcoming of affinity biosensors [132]. Using a lowaffinity ligand with a rapid dissociation rate has been suggested in the aim of performing continuous immunosensing [38] without the need for regeneration. However, this assumes the availability of multiple ligands for the analyte of interest, from which a suitable one with a weak affinity can be selected.

When taking a sample from a cell culture, minimal purification needs to be performed to at least remove the cells and cell debris, which could clog the flow cells of microfluidic SPR instruments. Dilution and filtration have both been automated to harness a SPR biosensor at-line from a bioreactor using a filter and a decantation column, along with a system of peristaltic pumps $[67,68]$. More work needs to be done to make at-line measurements readily available both in research and in the industry. We highlighted sequential assays combining concentration and kinetic analyses $[37,55]$ (discussed in detail in Section 3.4) as an example of a smart protocol aiming to gain more information in less injections and regenerations. We also noted the existence of automated sampling systems with integrated cell removal and liquid handling modules [133]. Those have been used mainly to perform chromatography measurements online from a bioreactor but could potentially be adapted to SPR biosensors in the future. We believe that such integrated instruments will play a bigger role in the PAT context.

Nonspecific binding is another problem that may hamper SPR assays. It occurs when materials accumulate on the sensor surface other than by forming an analyte-ligand interaction. It could be the analyte adsorbing on the biosensor surface. It could also be other compounds present in the injected solution, such as blood proteins (when injecting serum 
samples), binding the ligand, and/or the surface itself. SPR detects all mass accumulation near the surface, whether it comes from a specific binding or not. As such, using a ligand with a high specificity for the analyte is crucial. A robust double-referencing protocol [22] has been widely adopted, but the question of what to immobilize on the reference surface, if anything, remains. Section 7 will present a brief discussion of the antifouling materials. In concentration analysis assays, nonspecific binding is problematic, because it lowers the detection limits. The sensitivity can be improved by using oriented ligand immobilization strategies [15] or by using an inhibition (see Section 4.1) or a sandwich assay format (see Section 5). However, these assays increase the cost in time and materials, as they require sequential injections or a secondary antibody [45,72].

Mass transport limitations (MTL) can bias kinetic analyses by reducing the observed association and dissociation rate constants. MTL occurs when a large quantity of ligand molecules has been immobilized on the sensor surface. This speeds up the formation of analyte-ligand complexes, which depend on the concentration of analyte at proximity to the surface and the concentration of available ligand. Hence, the availability of analyte molecules near the surface can become limiting during the association phase when diffusion of the analyte towards the surface is slow in comparison to the binding rate. Moreover, rebinding can occur during the dissociation phase. In brief, the analyte molecules that just dissociated from a ligand molecule may rebind to another ligand molecule before they return to the bulk of the flow cell. Ideally, MTL should be avoided when performing a kinetic analysis, either by reducing the immobilized ligand density or by increasing the analyte injection flow rate. However, MTL can be accounted for when modeling the signal. On that note, an algorithm aiming to select the appropriate model (with or without MTL) while optimizing the injection times online has been suggested and has been shown to allow shorter experimental times while maintaining acceptable precision [27]. The need to account for MTL in the model is investigated via a dimensionless number that represents the ratio of the analyte-ligand complex formation rate to the analyte diffusion rate. Note that a concentration analysis, on the other hand, necessitates at least a partial MTL.

Heterogeneity in the ligand or analytes tends to complexify sensorgrams. This complicates both kinetic [15] and concentration analyses [33,37]. The quality of the immobilized ligand molecule should be as high as possible, and the selected ligand should exhibit a high specificity for the analyte under study. Improper folding or aggregation could cause SPR signals that are difficult to interpretate, and poor specificity could lead to high nonspecific contributions. This requirement is not as strong for the analyte, as long as denatured analyte molecules do not interact with either the ligand or the bioactive analyte molecules [15]. The analysis of SPR sensorgrams recorded with a heterogeneous system is briefly discussed in Section 8 .

The depth of the evanescent wave can also be limiting, as binding events occurring beyond the penetration depth are not sensed in SPR. Further, mass accumulation has a decaying influence on the SPR response with the distance from the metallic surface [33]. For this reason, the absolute calibration-free concentration analysis (CFCA) is influenced by the distribution of the analyte in the evanescent field. A form factor can be applied to counter this effect, but it is usually taken from empirical observations or obtained experimentally via calibrations, which is not ideal [32,33]. Additionally, diffusion of the analyte is hampered by the sensor matrix, which is not taken into account when estimating the diffusion coefficient in a solution [33]. Strategies involving multiple sequential injections could potentially lack reproducibility. Using smaller ligands, such as aptamers or antibody Fab fragments, could be a solution $[45,128]$.

\section{Recent Developments in SPR Instruments}

Designing SPR sensor chips with surfaces capable of being highly selective for the analyte of interest in complex media, such as human serum or cell lysates, remains one of the main challenges of SPR biosensing for monitoring [70,134]. In bioprocess monitoring, achieving low limits of detection is necessary to allow the monitoring of the early pro- 
duction and purification, as certain downstream processing steps have a diluting effect. As such, surfaces limiting nonspecific binding and, thus, offering more sensitivity are of interest. The idea is to replace the commercial matrices on which the ligand is typically immobilized with another matrix with better antifouling properties. Interested readers are invited to consult a recent extensive review on antifouling coatings used in SPR in the fields of food safety and diagnostics [70]. Briefly, most commonly used antifouling layers are composed of hydrogel or zwitterionic polymers or they constitute a self-assembled monolayer (SAM) often based on oligo ethylene glycol groups such as polyethylene glycol (PEG). The optimal antifouling material remains highly dependent on the characteristics of the media that is analyzed, and as such, a universal solution seems unlikely. In all cases, special care should be taken to ensure that the thickness of the antifouling material is well below the evanescent wave decay length. Otherwise, ligand molecules may be immobilized outside the detection range of the instrument. We note a very recent PEG-based surface exhibiting excellent antifouling properties when analyzing blood sera with a thickness of approximately $2 \mathrm{~nm}$ [71], which is well under the evanescent wave penetration depth (dependent on the incident light wavelength, around 200-300 $\mathrm{nm}$ [15]).

Other advances have been made to increase the throughput of SPR campaigns. Those were suggested mainly with drug screening in mind, but they could be appropriate for the simultaneous monitoring of multiple bioreactors or multiple bioprocess steps using different SPR surfaces with different ligands. The simultaneous measurement of multiple detection spots is possible with the surface plasmon resonance imaging (SPRi) technique. Briefly, rather than measuring the light intensity at a single point, a charge-coupled device (CCD) or complementary metal oxide semiconductor (CMOS) camera captures images of all the detection spots at every time step. These images can be analyzed to extract the SPR response at every detection spot. This allows 2D measurements across multiple channels rather than the typical 1D probing of a single flow cell. For more technical details on $\mathrm{SPRi}$, the reader is referred to a review on the recent advances in SPRi sensors [135]. SPRi allows for more throughput by parallelizing experiments, but the sensitivity can be slightly compromised, and sample handling and surface functionalization remain challenging.

Traditional SPR biosensors, such as those offered by Biacore (Cytiva), can take measurements in only four flow cells connected in series, with often only two actually being used. SPRi biosensors enable parallel injections at different SPR detection spots. The ProteOn XPR36 instrument (Bio-Rad Laboratories, Hercules, CA, USA; no longer commercially available) contains an array of six ligand channels crossed perpendicularly with six analyte channels, enabling the SPR measurements of 36 analyte-ligand couples in parallel. Different ligands or ligand concentrations can be immobilized on each of the six ligand channels, and different analytes or analyte concentrations can be injected in the six analyte channels [136]. ProteOn XPR36 was found to have approximately 10 times more throughput than a traditional Biacore T100 biosensor when performing a mAb screening campaign [137]. However, Biacore T100 was deemed to generate data of a higher quality, with more consistency. More recently, the Molecular Affinity Screening System (MASS-1) was introduced by Sierra Sensors (Bruker, Billerica, MA, USA) [138]. It contains eight parallel channels with two detection spots per channel: one active surface and one reference surface, limiting the distance between them. This biosensor measured similar kinetics and affinities compared to a Biacore 4000 biosensor when analyzing a panel of $\mathrm{mAbs}$ for differently sized antigens. Of interest, reproducible results could be obtained with very low ligand densities, which is sometimes necessary to avoid mass transport limitations when analyzing an analyte-ligand pair with a thermodynamic constant $K_{D}$ in the picomolar range. This is proof of the high sensitivity and low measurement noise of the MASS-1 as such low ligand density experiments lead to very weak SPR responses [138]. Moreover, the LSA platform (Carterra, Salt Lake City, UT, USA), which was released in 2018, enables the study of 384 antibodies simultaneously via SPRi [139].

Some work has been done in improving the portability of the SPR technology. This has paved the way to applications in point of care testing and environmental monitoring. In the 
context of bioprocess monitoring, limiting the distance between the process equipment and the monitoring devices is preferable, as it limits the handling of the samples. A portable optical-fiber-based SPR biosensor has been shown to be able to detect mAb levels both in the buffer and serum [140]. Further, low-cost SPR biosensors that can be harnessed to a smartphone have been suggested. In short, a SPR-sensing surface is linked to the phone's LED (light source) and camera (detector) through a system of fiber optics, and the samples are pumped in and out of the measurement channel. Such an arrangement enabled repeatable measurements with an appropriate, but slightly lower, sensitivity when compared to a traditional biosensor when measuring IgG-protein A interactions [141]. For more details, we point to a review on smartphone-based SPR biosensing [142].

Other developments come from new configurations of SPR biosensors. We note phase shift-based SPR biosensors that detect a rapid phase change between p- and spolarized light when SPR occurs. This phase change is more abrupt than the change in the reflected light intensity, allowing a greater sensitivity and wider dynamic range. The spatial resolution can also be enhanced, facilitating SPRi implementation $[73,74]$. Such a biosensor enabled a better sensitivity than with traditional SPR biosensors for influenza antibody biomarker detection [143]. SPR biosensors that detect phase shifts can be based on either optical heterodyne, ellipsometry, or interferometry. For more details on these concepts, interested readers are referred to relevant reviews [73,144].

Multi-parametric SPR (MP-SPR) biosensors record the whole SPR curve (rather than only the minimal point) to enable bulk effect removal without a reference and to measure various optical parameters, such as refractive indices of multiple surface layers. Notably, MP-SPR was used to measure the binding affinity of monoclonal antibody Adalimumab to Fc $\gamma$ RIIb and Fc $\gamma$ RIIIb in crude cell culture samples containing more than $10^{6}$ cells $/ \mathrm{mL}$. The affinity measured in the crude samples was similar to that of the purified samples [145]. In another study, liposome nanocarriers were immobilized on the surface, and undiluted human serum was injected. The formation of a protein corona on the surface of the liposomes could be tracked, and different formulations were compared [146].

\section{SPR Studies with Live Cells}

MP-SPR also enables the study of live cells. Cells can be seeded on a metallic surface by using fibronectin as an adhesion promoter. Living cells uptake of drugs [147], nanoparticles [148], and extracellular vesicles [149] has been monitored online in this fashion. The evanescent wave penetration is not deep enough to be impacted by the contact between the drugs or nanoparticles and the cell membrane. The SPR signal is caused by morphological changes and rearrangements of the intracellular materials that follow the binding event, leading to endocytosis [148]. Alternatively, configurations enabling a deeper penetration of the evanescent wave, called long-range SPR (LRSPR), have been suggested for these types of studies [150,151] and for the detection of bacteria [152]. However, LRSPR has yet to be commercialized [153]. Live cell responses to stimuli have also been probed with a biosensor combining SPR and impedance measurements by using a comb-shaped electrode [154].

Living cells can also been used as the analyte. One can aim to detect cell membrane antigens by injecting the cells on a SPR surface on which a specific antibody is immobilized. For example, the interaction between transmembrane TNF- $\alpha$ expressed on the membranes of Jurkat cells and anti-TNF agents immobilized on the sensor surface was studied by SPR [155]. The responses were found to be concentration-dependent and inhibited by free anti-TNF agents. On another note, stopping the flow completely after injecting the cells causes them to sediment, which allows them to be used as the ligand in a subsequent injection. Quantifying the secretion of cells is also possible, for example, by attaching microwell arrays on the sensor surface. With each well containing a single cell, and most of the cell's secreted species diffusing towards the SPR surface rather than the bulk, the ability of SPRi instruments to take measurements at multiple detection spots enables a comparison of the secretions of different cells [156]. For more details, the reader is referred to a recent review on the advances in the field of SPR cytometry [157]. 
Developments in the field of SPR cytometry are mainly tied to fundamental research, but they have possible implications in terms of validating the quality and effectiveness of manufactured bioproducts or nanoparticles, either during production or during the development stage.

\section{Recent Developments in SPR Data Analysis}

Some recent advances in SPR data analysis aim to analyze complex systems with more than one interaction occurring at the sensor surface. For example, injecting solutions containing a mixture of analytes that can bind to a common ligand was proposed as a way to increase the throughput of SPR biosensors in a drug screening framework. For this purpose, analytical methods enabling the extraction of the kinetic parameters of two analytes from sensorgrams recorded by injecting a single mixture of these analytes were suggested, and proof of concept was obtained on a model system [26,28]. Other than increasing the throughput, for which one willingly mixes the different analytes, one could also aim to identify the individual kinetic parameters of various (bio)molecules that are difficult to separate from each other. For instance, the various glycoforms of therapeutic monoclonal antibodies produced in mammalian cell cultures may not be readily separated. However, it is well-known that binding to their receptors is affected by their glycosylation state. Hence, studying this interaction via SPR leads to complex sensorgrams that cannot be properly analyzed with a simple Langmuir model [51-54].

In this mindset, the multi-analyte analysis was extended to the case of $N$ analytes [31]. This time, the aim was to analyze samples of analytes that are difficult to separate rather than to increase the throughput, as $N$ mixtures are required to elucidate $N$ analytes. This framework has only been applied to a model system composed of the enzyme carbonic anhydrase II as the ligand and several of its inhibitors as the analytes. However, possible applications include analyzing solutions of a given protein that is differently folded or glycosylated. A method for composition estimation, a potentially powerful tool in quality control, has also been suggested, but it requires a priori knowledge of the individual kinetic parameters of each analyte in the mixture with the ligand [31]. Other modeling advances enabled the analysis of complex sensorgrams hailing from analyte [29,30] or ligand heterogeneity [85-87]. These advances came with more complex interaction models, meaning more parameters to adjust. Care should be taken to avoid overfitting. Adding parameters will lead to better fits to recorded data, but it may not be significant. Broadly, if the mathematical model has no biological significance, the identified parameters are mostly meaningless.

Further, a similarity score has been proposed to assess how closely two given sensorgrams resemble each other [158]. As two analyte samples of similar quality should produce a similar binding response on a given SPR surface, computing the similarity score could prove an important asset in evaluating batch-to-batch variabilities and in validating a biosimilar by comparing its binding response to that of an approved reference biotherapeutic.

\section{Conclusions and Future Perspectives}

Surface plasmon resonance-based biosensors have long been established as a premiere tool for probing the interaction behavior between a solution species and a surfaceimmobilized species. The main advantages of the SPR technique are its ability to detect the interaction online and without a label. SPR is already in use in the pharmaceutical world as an investigative technique, for example, in drug screening campaigns to determine the best drug to bind a specific target amongst an array of candidates. With increasing demands in biotherapeutics and continuously stricter quality assurance directives from regulatory agencies, the frameworks of quality by design and quality by control pushed forward the need for powerful monitoring tools that can be used to acquire knowledge of the various critical parameters influencing the quality of bioproducts. In this context, we reviewed potential uses of the SPR technique as a monitoring tool. Three different types of bioprocesses were put forward: biotherapeutics production, vaccine production, 
and contaminant and bacteria detection in food samples. In all these cases, it seems that one of the main limitations remains the need for preprocessing of the samples: dilution, purification, or just simply handling the samples between the sampling site and the SPR instrument. Very few studies have shown the capability for harnessing a SPR biosensor to a bioreactor to automate sample taking, preprocessing, and SPR measurements online or at-line $[67,68]$. We noted, however, that some experimental setups have enabled the use of other analytical methods at-line of a bioreactor, such as chromatography and mass spectroscopy $[159,160]$ and in situ Raman spectroscopy [161]. The recent introduction of automated samplers and liquid handlers in integrated systems [133] has paved the way for online SPR, but more work needs to be done on the instruments themselves and related experimental protocols. Namely, the need for regeneration of the surface, the dilution of samples, and the removal of nonspecific contributions are all limiting. The portability of the instruments is being worked on, with several options available, but it seems that the precision and sensitivity may be slightly compromised in such systems.

Most applications of SPR that have been or could be used to monitor bioprocesses online involve estimating the solution concentrations of an analyte by immobilizing an analyte-specific ligand on the biosensing surface. This, of course, enables monitoring of the production, but it can also be used to track the yields of the purification steps. With evermore advances aiming to increase the sensitivity, SPR could be used to monitor the product concentration from early production all the way to the end of the downstream processing steps. A concentration analysis has been shown to be possible in complex media, such as blood sera and cell lysates, but the same cannot be said about kinetic analyses. To perform a kinetic analysis, a low density of the immobilized ligand is necessary to avoid mass transport limitations, rendering nonspecific contributions to the SPR signal more prominent. Performing a kinetic analysis online or at-line within a bioprocess could enable the monitoring of certain key quality attributes of bioproducts during production. As an example, the binding kinetics and affinity of monoclonal antibodies to Fc receptors are strongly dependent on their glycosylation profile, a CQA of mAbs [51]. We noted the existence of sequential assays $[37,55,102]$ in which, as an example, antibodies are first quantified in complex media via interactions with their immobilized antigen, followed by a second injection, this time of Fc region receptors in a defined buffer, to allow a kinetic analysis between the immobilized antibodies and the injected Fc receptors. Such ingenious protocols, and others in the future, will be necessary to allow kinetic analyses in crude samples for various types of bioproducts. This would open the way to the utilization of SPR biosensors in quality by design or even quality by control frameworks as process analytical technology.

Author Contributions: J.G., C.F.-N., and O.H. were responsible for conceptualizing and editing the manuscript. G.D.C. and Y.D. provided mentorship and valuable comments on the manuscript. All authors have read and agreed to the published version of the manuscript.

Funding: This research received no external funding.

Institutional Review Board Statement: Not applicable.

Informed Consent Statement: Not applicable.

Data Availability Statement: Not applicable.

Acknowledgments: This work was supported by the Natural Sciences and Engineering Research Council of Canada (stipend allocated to Catherine Forest-Nault and Jimmy Gaudreault via the NSERC-CREATE PrEEmiuM program). This work was supported by the Trans-MedTech Institute (NanoBio Technology Platform) and its main funding partner, the Canada First Research Excellence Fund.

Conflicts of Interest: The authors declare no conflict of interest. 


\section{References}

1. Lu, R.-M.; Hwang, Y.-C.; Liu, I.J.; Lee, C.-C.; Tsai, H.-Z.; Li, H.-J.; Wu, H.-C. Development of therapeutic antibodies for the treatment of diseases. J. Biomed. Sci. 2020, 27, 1. [CrossRef]

2. Gherghescu, I.; Delgado-Charro, M.B. The Biosimilar Landscape: An Overview of Regulatory Approvals by the EMA and FDA. Pharmaceutics 2021, 13, 48. [CrossRef]

3. U. S. Food and Drug Administration. Guidance for Industry: Q8(R2) Pharmaceutical Development; U. S. Food and Drug Administration: Rockville, MD, USA, 2009.

4. Yu, L.X.; Amidon, G.; Khan, M.A.; Hoag, S.W.; Polli, J.; Raju, G.K.; Woodcock, J. Understanding pharmaceutical quality by design. AAPS J 2014, 16, 771-783. [CrossRef]

5. Grangeia, H.B.; Silva, C.; Simões, S.P.; Reis, M.S. Quality by design in pharmaceutical manufacturing: A systematic review of current status, challenges and future perspectives. Eur. J. Pharm. Biopharm. 2020, 147, 19-37. [CrossRef]

6. Yu, L.X.; Kopcha, M. The future of pharmaceutical quality and the path to get there. Int. J. Pharm. 2017, 528, 354-359. [CrossRef] [PubMed]

7. Sommeregger, W.; Sissolak, B.; Kandra, K.; von Stosch, M.; Mayer, M.; Striedner, G. Quality by control: Towards model predictive control of mammalian cell culture bioprocesses. Biotechnol. J. 2017, 12, 1600546. [CrossRef]

8. Su, Q.; Ganesh, S.; Moreno, M.; Bommireddy, Y.; Gonzalez, M.; Reklaitis, G.V.; Nagy, Z.K. A perspective on Quality-by-Control $(\mathrm{QbC})$ in pharmaceutical continuous manufacturing. Comput. Chem. Eng. 2019, 125, 216-231. [CrossRef]

9. U. S. Food and Drug Administration. Guidance for Industry: PAT-A Framework for Innovative Pharmaceutical Development, Manufacturing, and Quality Assurance; U. S. Food and Drug Administration: Rockville, MD, USA, 2004.

10. Simon, L.L.; Pataki, H.; Marosi, G.; Meemken, F.; Hungerbühler, K.; Baiker, A.; Tummala, S.; Glennon, B.; Kuentz, M.; Steele, G.; et al. Assessment of Recent Process Analytical Technology (PAT) Trends: A Multiauthor Review. Org. Process Res. Dev. 2015, 19, 3-62. [CrossRef]

11. Helgers, H.; Schmidt, A.; Lohmann, L.J.; Vetter, F.L.; Juckers, A.; Jensch, C.; Mouellef, M.; Zobel-Roos, S.; Strube, J. Towards Autonomous Operation by Advanced Process Control-Process Analytical Technology for Continuous Biologics Antibody Manufacturing. Processes 2021, 9, 172. [CrossRef]

12. Kretschmann, E.; Raether, H. Notizen: Radiative Decay of Non Radiative Surface Plasmons Excited by Light. Z. Nat. A 1968, 23, 2135-2136. [CrossRef]

13. Kretschmann, E. Decay of non radiative surface plasmons into light on rough silver films. Comparison of experimental and theoretical results. Opt. Commun. 1972, 6, 185-187. [CrossRef]

14. Otto, A. Excitation of nonradiative surface plasma waves in silver by the method of frustrated total reflection. Z. Phys. A Hadron. Nucl. 1968, 216, 398-410. [CrossRef]

15. De Crescenzo, G.; Boucher, C.; Durocher, Y.; Jolicoeur, M. Kinetic Characterization by Surface Plasmon Resonance-Based Biosensors: Principle and Emerging Trends. Cell. Mol. Bioeng. 2008, 1, 204-215. [CrossRef]

16. Homola, J. Present and future of surface plasmon resonance biosensors. Anal. Bioanal. Chem. 2003, 377, 528-539. [CrossRef] [PubMed]

17. Couture, M.; Zhao, S.S.; Masson, J.-F. Modern surface plasmon resonance for bioanalytics and biophysics. Phys. Chem. Chem. Phys. 2013, 15, 11190-11216. [CrossRef]

18. Wang, D.S.; Fan, S.K. Microfluidic Surface Plasmon Resonance Sensors: From Principles to Point-of-Care Applications. Sensors 2016, 16, 1175. [CrossRef]

19. Prabowo, B.A.; Purwidyantri, A.; Liu, K.-C. Surface Plasmon Resonance Optical Sensor: A Review on Light Source Technology. Biosensors 2018, 8, 80. [CrossRef]

20. Shrivastav, A.M.; Cvelbar, U.; Abdulhalim, I. A comprehensive review on plasmonic-based biosensors used in viral diagnostics. Commun. Biol. 2021, 4, 70. [CrossRef]

21. Guo, X. Surface plasmon resonance based biosensor technique: A review. J. Biophotonics 2012, 5, 483-501. [CrossRef]

22. Myszka, D.G. Improving biosensor analysis. J. Mol. Recognit. JMR 1999, 12, 279-284. [CrossRef]

23. Önell, A.; Andersson, K. Kinetic determinations of molecular interactions using Biacore-Minimum data requirements for efficient experimental design. J. Mol. Recognit. 2005, 18, 307-317. [CrossRef] [PubMed]

24. Karlsson, R.; Katsamba, P.S.; Nordin, H.; Pol, E.; Myszka, D.G. Analyzing a kinetic titration series using affinity biosensors. Anal. Biochem. 2006, 349, 136-147. [CrossRef] [PubMed]

25. De Crescenzo, G.; Woodward, L.; Srinivasan, B. Online optimization of surface plasmon resonance-based biosensor experiments for improved throughput and confidence. J. Mol. Recognit. 2008, 21, 256-266. [CrossRef] [PubMed]

26. Mehand, M.S.; De Crescenzo, G.; Srinivasan, B. Increasing throughput of surface plasmon resonance-based biosensors by multiple analyte injections. J. Mol. Recognit. JMR 2012, 25, 208-215. [CrossRef]

27. Si Mehand, M.; De Crescenzo, G.; Srinivasan, B. On-line kinetic model discrimination for optimized surface plasmon resonance experiments. J. Mol. Recognit. JMR 2014, 27, 276-284. [CrossRef]

28. Mehand, M.S.; Srinivasan, B.; De Crescenzo, G. Optimizing Multiple Analyte Injections in Surface Plasmon Resonance Biosensors with Analytes having Different Refractive Index Increments. Sci. Rep. 2015, 5, 15855. [CrossRef]

29. Zhang, Y.; Forssén, P.; Fornstedt, T.; Gulliksson, M.; Dai, X. An adaptive regularization algorithm for recovering the rate constant distribution from biosensor data. Inverse Probl. Sci. Eng. 2018, 26, 1464-1489. [CrossRef] 
30. Forssén, P.; Multia, E.; Samuelsson, J.; Andersson, M.; Aastrup, T.; Altun, S.; Wallinder, D.; Wallbing, L.; Liangsupree, T.; Riekkola, M.-L.; et al. Reliable Strategy for Analysis of Complex Biosensor Data. Anal. Chem. 2018, 90, 5366-5374. [CrossRef]

31. Gaudreault, J.; Liberelle, B.; Durocher, Y.; Henry, O.; De Crescenzo, G. Determination of the composition of heterogeneous binder solutions by surface plasmon resonance biosensing. Sci. Rep. 2021, 11, 3685. [CrossRef]

32. Pol, E.; Roos, H.; Markey, F.; Elwinger, F.; Shaw, A.; Karlsson, R. Evaluation of calibration-free concentration analysis provided by Biacore $^{\mathrm{TM}}$ systems. Anal. Biochem. 2016, 510, 88-97. [CrossRef]

33. Karlsson, R. Biosensor binding data and its applicability to the determination of active concentration. Biophys. Rev. 2016, 8, 347-358. [CrossRef]

34. Karlsson, R.; Roos, H.; Fägerstam, L.; Persson, B. Kinetic and Concentration Analysis Using BIA Technology. Methods 1994, 6, 99-110. [CrossRef]

35. Christensen, L.L. Theoretical analysis of protein concentration determination using biosensor technology under conditions of partial mass transport limitation. Anal. Biochem. 1997, 249, 153-164. [CrossRef]

36. Vaisocherová, H.; Faca, V.M.; Taylor, A.D.; Hanash, S.; Jiang, S. Comparative study of SPR and ELISA methods based on analysis of CD166/ALCAM levels in cancer and control human sera. Biosens. Bioelectron. 2009, 24, 2143-2148. [CrossRef]

37. Karlsson, R.; Fridh, V.; Frostell, Å. Surrogate potency assays: Comparison of binding profiles complements dose response curves for unambiguous assessment of relative potencies. J. Pharm. Anal. 2018, 8, 138-146. [CrossRef]

38. Mandenius, C.F.; Wang, R.; Aldén, A.; Bergström, G.; Thébault, S.; Lutsch, C.; Ohlson, S. Monitoring of influenza virus hemagglutinin in process samples using weak affinity ligands and surface plasmon resonance. Anal. Chim. Acta 2008, 623, 66-75. [CrossRef]

39. Nilsson, C.E.; Abbas, S.; Bennemo, M.; Larsson, A.; Hämäläinen, M.D.; Frostell-Karlsson, A. A novel assay for influenza virus quantification using surface plasmon resonance. Vaccine 2010, 28, 759-766. [CrossRef]

40. Khurana, S.; King, L.R.; Manischewitz, J.; Coyle, E.M.; Golding, H. Novel antibody-independent receptor-binding SPR-based assay for rapid measurement of influenza vaccine potency. Vaccine 2014, 32, 2188-2197. [CrossRef]

41. Durous, L.; Julien, T.; Padey, B.; Traversier, A.; Rosa-Calatrava, M.; Blum, L.J.; Marquette, C.A.; Petiot, E. SPRi-based hemagglutinin quantitative assay for influenza vaccine production monitoring. Vaccine 2019, 37, 1614-1621. [CrossRef]

42. Bruce-Staskal, P.J.; Woods, R.M.; Borisov, O.V.; Massare, M.J.; Hahn, T.J. Corrigendum to “Hemagglutinin from multiple divergent influenza A and B viruses bind to a distinct branched, sialylated poly-LacNAc glycan by surface plasmon resonance" [Vaccine 38(43) (2020) 6757-6765]. Vaccine 2021, 39, 1544-1545. [CrossRef]

43. Poltronieri, P.; Mezzolla, V.; Primiceri, E.; Maruccio, G. Biosensors for the Detection of Food Pathogens. Foods 2014, 3, 511-526. [CrossRef] [PubMed]

44. Mattiasson, B.; Teeparuksapun, K.; Hedström, M. Immunochemical binding assays for detection and quantification of trace impurities in biotechnological production. Trends Biotechnol. 2010, 28, 20-27. [CrossRef] [PubMed]

45. Dudak, F.C.; Boyaci, I.H. Rapid and label-free bacteria detection by surface plasmon resonance (SPR) biosensors. Biotechnol. J. 2009, 4, 1003-1011. [CrossRef] [PubMed]

46. Wang, Y.; Ye, Z.; Si, C.; Ying, Y. Monitoring of Escherichia coli O157:H7 in food samples using lectin based surface plasmon resonance biosensor. Food Chem. 2013, 136, 1303-1308. [CrossRef]

47. Bhandari, D.; Chen, F.-C.; Bridgman, R.C. Detection of Salmonella Typhimurium in Romaine Lettuce Using a Surface Plasmon Resonance Biosensor. Biosensors 2019, 9, 94. [CrossRef]

48. Masdor, N.A.; Altintas, Z.; Tothill, I.E. Surface Plasmon Resonance Immunosensor for the Detection of Campylobacter jejuni. Chemosensors 2017, 5, 16. [CrossRef]

49. Masdor, N.A.; Altintas, Z.; Shukor, M.Y.; Tothill, I.E. Subtractive inhibition assay for the detection of Campylobacter jejuni in chicken samples using surface plasmon resonance. Sci. Rep. 2019, 9, 13642. [CrossRef]

50. Raghu, H.V.; Kumar, N. Rapid Detection of Listeria monocytogenes in Milk by Surface Plasmon Resonance Using Wheat Germ Agglutinin. Food Anal. Methods 2020, 13, 982-991. [CrossRef]

51. Forest-Nault, C.; Gaudreault, J.; Henry, O.; Durocher, Y.; De Crescenzo, G. On the Use of Surface Plasmon Resonance Biosensing to Understand IgG-Fc $\gamma$ R Interactions. Int. J. Mol. Sci. 2021, 22, 6616. [CrossRef]

52. Cambay, F.; Henry, O.; Durocher, Y.; De Crescenzo, G. Impact of N-glycosylation on Fc $\gamma$ receptor/IgG interactions: Unravelling differences with an enhanced surface plasmon resonance biosensor assay based on coiled-coil interactions. $m A b s$ 2019, 11, 435-452. [CrossRef]

53. Cambay, F.; Forest-Nault, C.; Dumoulin, L.; Seguin, A.; Henry, O.; Durocher, Y.; De Crescenzo, G. Glycosylation of Fc $\gamma$ receptors influences their interaction with various IgG1 glycoforms. Mol. Immunol. 2020, 121, 144-158. [CrossRef] [PubMed]

54. Subedi, G.P.; Barb, A.W. The immunoglobulin G1 N-glycan composition affects binding to each low affinity Fc $\gamma$ receptor. $m A b s$ 2016, 8, 1512-1524. [CrossRef] [PubMed]

55. Dorion-Thibaudeau, J.; Durocher, Y.; De Crescenzo, G. Quantification and simultaneous evaluation of the bioactivity of antibody produced in $\mathrm{CHO}$ cell culture-The use of the ectodomain of Fc $\gamma \mathrm{RI}$ and surface plasmon resonance-based biosensor. Mol. Immunol. 2017, 82, 46-49. [CrossRef] [PubMed]

56. Wang, W.; Soriano, B.; Chen, Q. Glycan profiling of proteins using lectin binding by Surface Plasmon Resonance. Anal. Biochem. 2017, 538, 53-63. [CrossRef] [PubMed] 
57. Wang, H.; Shi, J.; Wang, Y.; Cai, K.; Wang, Q.; Hou, X.; Guo, W.; Zhang, F. Development of biosensor-based SPR technology for biological quantification and quality control of pharmaceutical proteins. J. Pharm. Biomed. Anal. 2009, 50, 1026-1029. [CrossRef] [PubMed]

58. Coty, J.B.; Noiray, M.; Vauthier, C. Assessment of Complement Activation by Nanoparticles: Development of a SPR Based Method and Comparison with Current High Throughput Methods. Pharm. Res. 2018, 35, 129. [CrossRef] [PubMed]

59. Huang, L.; Ding, L.; Zhou, J.; Chen, S.; Chen, F.; Zhao, C.; Xu, J.; Hu, W.; Ji, J.; Xu, H.; et al. One-step rapid quantification of SARS-CoV-2 virus particles via low-cost nanoplasmonic sensors in generic microplate reader and point-of-care device. Biosens. Bioelectron. 2021, 171, 112685. [CrossRef]

60. Mauriz, E. Recent Progress in Plasmonic Biosensing Schemes for Virus Detection. Sensors 2020, 20, 4745. [CrossRef]

61. Singh, P. Surface Plasmon Resonance: A Boon for Viral Diagnostics. Ref. Modul. Life Sci. 2017. [CrossRef]

62. Bellassai, N.; D'Agata, R.; Jungbluth, V.; Spoto, G. Surface Plasmon Resonance for Biomarker Detection: Advances in Non-invasive Cancer Diagnosis. Front. Chem. 2019, 7, 570. [CrossRef]

63. Souto, D.E.P.; Volpe, J.; Gonçalves, C.d.C.; Ramos, C.H.I.; Kubota, L.T. A brief review on the strategy of developing SPR-based biosensors for application to the diagnosis of neglected tropical diseases. Talanta 2019, 205, 120122. [CrossRef] [PubMed]

64. Brulé, T.; Granger, G.; Bukar, N.; Deschênes-Rancourt, C.; Havard, T.; Schmitzer, A.R.; Martel, R.; Masson, J.-F. A field-deployed surface plasmon resonance (SPR) sensor for RDX quantification in environmental waters. Analyst 2017, 142, 2161-2168. [CrossRef] [PubMed]

65. Zschätzsch, M.; Ritter, P.; Henseleit, A.; Wiehler, K.; Malik, S.; Bley, T.; Walther, T.; Boschke, E. Monitoring bioactive and total antibody concentrations for continuous process control by surface plasmon resonance spectroscopy. Eng. Life Sci. 2019, 19, 681-690. [CrossRef] [PubMed]

66. Frostell, Å.; Mattsson, A.; Eriksson, Å.; Wallby, E.; Kärnhall, J.; Illarionova, N.B.; Estmer Nilsson, C. Nine surface plasmon resonance assays for specific protein quantitation during cell culture and process development. Anal. Biochem. 2015, 477, 1-9. [CrossRef] [PubMed]

67. Chavane, N.; Jacquemart, R.; Hoemann, C.D.; Jolicoeur, M.; De Crescenzo, G. At-line quantification of bioactive antibody in bioreactor by surface plasmon resonance using epitope detection. Anal. Biochem. 2008, 378, 158-165. [CrossRef]

68. Jacquemart, R.; Chavane, N.; Durocher, Y.; Hoemann, C.; De Crescenzo, G.; Jolicoeur, M. At-line monitoring of bioreactor protein production by surface plasmon resonance. Biotechnol. Bioeng. 2008, 100, 184-188. [CrossRef]

69. Beeg, M.; Nobili, A.; Orsini, B.; Rogai, F.; Gilardi, D.; Fiorino, G.; Danese, S.; Salmona, M.; Garattini, S.; Gobbi, M. A Surface Plasmon Resonance-based assay to measure serum concentrations of therapeutic antibodies and anti-drug antibodies. Sci. Rep. 2019, 9, 2064. [CrossRef]

70. D'Agata, R.; Bellassai, N.; Jungbluth, V.; Spoto, G. Recent Advances in Antifouling Materials for Surface Plasmon Resonance Biosensing in Clinical Diagnostics and Food Safety. Polymers 2021, 13, 1929. [CrossRef]

71. D'Agata, R.; Bellassai, N.; Giuffrida, M.C.; Aura, A.M.; Petri, C.; Kögler, P.; Vecchio, G.; Jonas, U.; Spoto, G. A new ultralow fouling surface for the analysis of human plasma samples with surface plasmon resonance. Talanta 2021, 221, 121483. [CrossRef]

72. Schasfoort, R.B.M. Introduction to Surface Plasmon Resonance. In Handbook of Surface Plasmon Resonance, 2nd ed.; Schasfoort, R.B.M., Ed.; The Royal Society of Chemistry: London, UK, 2017; pp. 1-26.

73. Deng, S.; Wang, P.; Yu, X. Phase-Sensitive Surface Plasmon Resonance Sensors: Recent Progress and Future Prospects. Sensors 2017, 17, 2819. [CrossRef]

74. Kashif, M.; Bakar, A.A.A.; Arsad, N.; Shaari, S. Development of phase detection schemes based on surface plasmon resonance using interferometry. Sensors 2014, 14, 15914-15938. [CrossRef] [PubMed]

75. Stenberg, E.; Persson, B.; Roos, H.; Urbaniczky, C. Quantitative determination of surface concentration of protein with surface plasmon resonance using radiolabeled proteins. J. Colloid Interface Sci. 1991, 143, 513-526. [CrossRef]

76. Affinité Instruments. Unleashing Label Free Sensing-Surface Plasmon Resonance for Rapid Testing. Available online: https: / / www.affiniteinstruments.com/ (accessed on 16 September 2021).

77. Cytiva. Biacore SPR-Surface Plasmon Resonance Interaction Analysis. Available online: https://www.cytivalifesciences.com/ en/us/solutions / protein-research/interaction-analysis-with-biacore-surface-plasmon-resonance-spr (accessed on 16 September 2021).

78. BioNavis. BioNavis: Enter the world of MP-SPR and find a solution to your research needs! Available online: https://www. bionavis.com/ (accessed on 16 September 2021).

79. Biosensing Instrument. Biosensing Instrument Offers Bioanalytical Tools to Accelerate Drug Discovery Research. Available online: https:/ / biosensingusa.com/ (accessed on 16 September 2021).

80. Carterra. High Throughput Antibody Screening and Characterization. Available online: https://carterra-bio.com/ (accessed on 16 September 2021).

81. Reichert Technologies. Discover the Reichert SPR Difference. Available online: https://www.reichertspr.com/ (accessed on 16 September 2021).

82. Bruker. Surface Plasmon Resonance for High-Throughput Analysis. Available online: https://www.bruker.com/en/productsand-solutions / surface-plasmon-resonance.html (accessed on 16 September 2021).

83. Andersson, K.; Hämäläinen, M.; Malmqvist, M. Identification and Optimization of Regeneration Conditions for Affinity-Based Biosensor Assays. A Multivariate Cocktail Approach. Anal. Chem. 1999, 71, 2475-2481. [CrossRef] [PubMed] 
84. Goode, J.A.; Rushworth, J.V.H.; Millner, P.A. Biosensor Regeneration: A Review of Common Techniques and Outcomes. Langmuir 2015, 31, 6267-6276. [CrossRef] [PubMed]

85. Svitel, J.; Balbo, A.; Mariuzza, R.A.; Gonzales, N.R.; Schuck, P. Combined Affinity and Rate Constant Distributions of Ligand Populations from Experimental Surface Binding Kinetics and Equilibria. Biophys. J. 2003, 84, 4062-4077. [CrossRef]

86. Svitel, J.; Boukari, H.; Van Ryk, D.; Willson, R.C.; Schuck, P. Probing the Functional Heterogeneity of Surface Binding Sites by Analysis of Experimental Binding Traces and the Effect of Mass Transport Limitation. Biophys. J. 2007, 92, 1742-1758. [CrossRef]

87. Gorshkova, I.I.; Svitel, J.; Razjouyan, F.; Schuck, P. Bayesian Analysis of Heterogeneity in the Distribution of Binding Properties of Immobilized Surface Sites. Langmuir 2008, 24, 11577-11586. [CrossRef]

88. Khalifa, M.B.; Choulier, L.; Lortat-Jacob, H.; Altschuh, D.; Vernet, T. BIACORE Data Processing: An Evaluation of the Global Fitting Procedure. Anal. Biochem. 2001, 293, 194-203. [CrossRef]

89. De Crescenzo, G.; Grothe, S.; Zwaagstra, J.; Tsang, M.; O'Connor-McCourt, M.D. Real-time monitoring of the interactions of transforming growth factor-beta (TGF-beta ) isoforms with latency-associated protein and the ectodomains of the TGF-beta type II and III receptors reveals different kinetic models and stoichiometries of binding. J. Biol. Chem. 2001, 276, 29632-29643. [CrossRef]

90. Sprague, E.R.; Martin, W.L.; Bjorkman, P.J. pH dependence and stoichiometry of binding to the Fc region of IgG by the herpes simplex virus Fc receptor gE-gI. J. Biol. Chem. 2004, 279, 14184-14193. [CrossRef]

91. Giannetti, A.M.; Snow, P.M.; Zak, O.; Björkman, P.J. Mechanism for Multiple Ligand Recognition by the Human Transferrin Receptor. PLoS Biol. 2003, 1, e51. [CrossRef] [PubMed]

92. Müller, K.M.; Arndt, K.M.; Plückthun, A. Model and simulation of multivalent binding to fixed ligands. Anal. Biochem. 1998, 261, 149-158. [CrossRef] [PubMed]

93. De Crescenzo, G.; Grothe, S.; Lortie, R.; Debanne, M.T.; O'Connor-McCourt, M. Real-Time Kinetic Studies on the Interaction of Transforming Growth Factor $\alpha$ with the Epidermal Growth Factor Receptor Extracellular Domain Reveal a Conformational Change Model. Biochemistry 2000, 39, 9466-9476. [CrossRef] [PubMed]

94. Futamura, M.; Dhanasekaran, P.; Handa, T.; Phillips, M.C.; Lund-Katz, S.; Saito, H. Two-step mechanism of binding of apolipoprotein $\mathrm{E}$ to heparin: Implications for the kinetics of apolipoprotein E-heparan sulfate proteoglycan complex formation on cell surfaces. J. Biol. Chem. 2005, 280, 5414-5422. [CrossRef] [PubMed]

95. Bio-Rad Laboratories. ProteOn XPR36 Experimental Design and Application Guide; Bio-Rad Laboratoires: Hercules, CA, USA, 2014.

96. Goldstein, B.; Coombs, D.; He, X.; Pineda, A.R.; Wofsy, C. The influence of transport on the kinetics of binding to surface receptors: Application to cells and BIAcore. J. Mol. Recognit. JMR 1999, 12, 293-299. [CrossRef]

97. Sjoelander, S.; Urbaniczky, C. Integrated fluid handling system for biomolecular interaction analysis. Anal. Chem. 1991, 63, 2338-2345. [CrossRef]

98. Cytiva. Accurate Comparability Assessment of a Biosimilar Interferon in Process Development; Cytiva: Marlborough, MA, USA, 2020.

99. Hu, T.; Wu, L.; Sun, X.; Su, P.; Yang, Y. Comparative study on quantitation of human myoglobin by both isotope dilution mass spectrometry and surface plasmon resonance based on calibration-free analysis. Anal. Bioanal. Chem. 2020, 412, $2777-2784$. [CrossRef]

100. Imamura, H.; Honda, S. Calibration-free concentration analysis for an analyte prone to self-association. Anal. Biochem. 2017, 516, 61-64. [CrossRef]

101. Hossler, P.; Khattak, S.F.; Li, Z.J. Optimal and consistent protein glycosylation in mammalian cell culture. Glycobiology 2009, 19, 936-949. [CrossRef]

102. Canziani, G.A.; Klakamp, S.; Myszka, D.G. Kinetic screening of antibodies from crude hybridoma samples using Biacore. Anal. Biochem. 2004, 325, 301-307. [CrossRef]

103. Wu, L.; He, Y.; Hu, Y.; Lu, H.; Cao, Z.; Yi, X.; Wang, J. Real-time surface plasmon resonance monitoring of site-specific phosphorylation of p53 protein and its interaction with MDM2 protein. Analyst 2019, 144, 6033-6040. [CrossRef] [PubMed]

104. Cytiva. Biacore Systems in Discovery and Early-Stage Development of Biotherapeutics Antibodies; Cytiva: Marlborough, MA, USA, 2016.

105. Yun, S.; Lee, S.; Park, J.P.; Choo, J.; Lee, E.K. Modification of phage display technique for improved screening of high-affinity binding peptides. J. Biotechnol. 2019, 289, 88-92. [CrossRef]

106. Zhao, A.; Tohidkia, M.R.; Siegel, D.L.; Coukos, G.; Omidi, Y. Phage antibody display libraries: A powerful antibody discovery platform for immunotherapy. Crit. Rev. Biotechnol. 2016, 36, 276-289. [CrossRef] [PubMed]

107. Munke, A.; Persson, J.; Weiffert, T.; De Genst, E.; Meisl, G.; Arosio, P.; Carnerup, A.; Dobson, C.M.; Vendruscolo, M.; Knowles, T.P.J.; et al. Phage display and kinetic selection of antibodies that specifically inhibit amyloid self-replication. Proc. Natl. Acad. Sci. USA 2017, 114, 6444-6449. [CrossRef] [PubMed]

108. Jackson, S.; Lentino, J.; Kopp, J.; Murray, L.; Ellison, W.; Rhee, M.; Shockey, G.; Akella, L.; Erby, K.; Heyward, W.L.; et al. Immunogenicity of a two-dose investigational hepatitis B vaccine, HBsAg-1018, using a toll-like receptor 9 agonist adjuvant compared with a licensed hepatitis B vaccine in adults. Vaccine 2018, 36, 668-674. [CrossRef] [PubMed]

109. Quinn, J.G.; Pitts, K.E.; Steffek, M.; Mulvihill, M.M. Determination of Affinity and Residence Time of Potent Drug-Target Complexes by Label-free Biosensing. J. Med. Chem. 2018, 61, 5154-5161. [CrossRef] [PubMed]

110. Frostell-Karlsson, A.; Remaeus, A.; Roos, H.; Andersson, K.; Borg, P.; Hämäläinen, M.; Karlsson, R. Biosensor analysis of the interaction between immobilized human serum albumin and drug compounds for prediction of human serum albumin binding levels. J. Med. Chem. 2000, 43, 1986-1992. [CrossRef] 
111. Gonzales, N.R.; Schuck, P.; Schlom, J.; Kashmiri, S.V. Surface plasmon resonance-based competition assay to assess the sera reactivity of variants of humanized antibodies. J. Immunol. Methods 2002, 268, 197-210. [CrossRef]

112. Ritter, G.; Cohen, L.S.; Williams, C., Jr.; Richards, E.C.; Old, L.J.; Welt, S. Serological analysis of human anti-human antibody responses in colon cancer patients treated with repeated doses of humanized monoclonal antibody A33. Cancer Res. 2001, 61, 6851-6859.

113. Wang, W.; Lu, P.; Fang, Y.; Hamuro, L.; Pittman, T.; Carr, B.; Hochman, J.; Prueksaritanont, T. Monoclonal antibodies with identical Fc sequences can bind to FcRn differentially with pharmacokinetic consequences. Drug Metab. Dispos. 2011, 39, 1469-1477. [CrossRef]

114. Pyzik, M.; Sand, K.M.K.; Hubbard, J.J.; Andersen, J.T.; Sandlie, I.; Blumberg, R.S. The Neonatal Fc Receptor (FcRn): A Misnomer? Front. Immunol. 2019, 10, 1540. [CrossRef] [PubMed]

115. Lu, Y.; Vernes, J.M.; Chiang, N.; Ou, Q.; Ding, J.; Adams, C.; Hong, K.; Truong, B.T.; Ng, D.; Shen, A.; et al. Identification of IgG(1) variants with increased affinity to Fc $\gamma$ RIIIa and unaltered affinity to Fc $\gamma$ RI and FcRn: Comparison of soluble receptor-based and cell-based binding assays. J. Immunol. Methods 2011, 365, 132-141. [CrossRef] [PubMed]

116. World Health Organization. Influenza Vaccine Response during the Start of a Pandemic: Report of a WHO Informal Consultation Held in Geneve, Switzerland, 29 June-1 July 2015; World Health Organization: Geneva, Switzerland, 2016; Volume 2016.

117. Suenaga, E.; Mizuno, H.; Penmetcha, K.K. Monitoring influenza hemagglutinin and glycan interactions using surface plasmon resonance. Biosens. Bioelectron. 2012, 32, 195-201. [CrossRef] [PubMed]

118. Abadian, P.N.; Yildirim, N.; Gu, A.Z.; Goluch, E.D. SPRi-based adenovirus detection using a surrogate antibody method. Biosens . Bioelectron. 2015, 74, 808-814. [CrossRef] [PubMed]

119. Roldão, A.; Mellado, M.C.; Castilho, L.R.; Carrondo, M.J.; Alves, P.M. Virus-like particles in vaccine development. Expert Rev. Vaccines 2010, 9, 1149-1176. [CrossRef] [PubMed]

120. Nooraei, S.; Bahrulolum, H.; Hoseini, Z.S.; Katalani, C.; Hajizade, A.; Easton, A.J.; Ahmadian, G. Virus-like particles: Preparation, immunogenicity and their roles as nanovaccines and drug nanocarriers. J. Nanobiotechnol. 2021, 19, 59. [CrossRef]

121. Thompson, C.M.; Petiot, E.; Lennaertz, A.; Henry, O.; Kamen, A.A. Analytical technologies for influenza virus-like particle candidate vaccines: Challenges and emerging approaches. Virol. J. 2013, 10, 141. [CrossRef]

122. Chang, J. Adenovirus Vectors: Excellent Tools for Vaccine Development. Immune Netw 2021, 21, e6. [CrossRef]

123. Glick, G.D.; Toogood, P.L.; Wiley, D.C.; Skehel, J.J.; Knowles, J.R. Ligand recognition by influenza virus. The binding of bivalent sialosides. J. Biol. Chem. 1991, 266, 23660-23669. [CrossRef]

124. Connor, R.J.; Kawaoka, Y.; Webster, R.G.; Paulson, J.C. Receptor specificity in human, avian, and equine H2 and H3 influenza virus isolates. Virology 1994, 205, 17-23. [CrossRef]

125. Ohlson, S.; Jungar, C.; Strandh, M.; Mandenius, C.-F. Continuous weak-affinity immunosensing. Trends Biotechnol. 2000, 18, 49-52. [CrossRef]

126. Tawil, N.; Sacher, E.; Mandeville, R.; Meunier, M. Bacteriophages: Biosensing tools for multi-drug resistant pathogens. Analyst 2014, 139, 1224-1236. [CrossRef] [PubMed]

127. Nanduri, V.; Bhunia, A.K.; Tu, S.I.; Paoli, G.C.; Brewster, J.D. SPR biosensor for the detection of L. monocytogenes using phage-displayed antibody. Biosens. Bioelectron. 2007, 23, 248-252. [CrossRef] [PubMed]

128. Cho, I.H.; Ku, S. Current Technical Approaches for the Early Detection of Foodborne Pathogens: Challenges and Opportunities. Int. J. Mol. Sci. 2017, 18, 2078. [CrossRef] [PubMed]

129. Zheng, X.; Gao, S.; Wu, J.; Hu, X. Recent Advances in Aptamer-Based Biosensors for Detection of Pseudomonas aeruginosa. Front. Microbiol. 2020, 11, 5229. [CrossRef]

130. Puttharugsa, C.; Wangkam, T.; Huangkamhang, N.; Gajanandana, O.; Himananto, O.; Sutapun, B.; Amarit, R.; Somboonkaew, A.; Srikhirin, T. Development of surface plasmon resonance imaging for detection of Acidovorax avenae subsp. citrulli (Aac) using specific monoclonal antibody. Biosens. Bioelectron. 2011, 26, 2341-2346. [CrossRef] [PubMed]

131. Taylor, A.D.; Ladd, J.; Homola, J.; Jiang, S. Surface Plasmon Resonance (SPR) Sensors for the Detection of Bacterial Pathogens. In Principles of Bacterial Detection: Biosensors, Recognition Receptors and Microsystems; Zourob, M., Elwary, S., Turner, A., Eds.; Springer: New York, NY, USA, 2008; pp. 83-108.

132. Kastenhofer, J.; Rajamanickam, V.; Libiseller-Egger, J.; Spadiut, O. Monitoring and control of E. coli cell integrity. J. Biotechnol. 2021, 329, 1-12. [CrossRef]

133. Hofer, A.; Kroll, P.; Barmettler, M.; Herwig, C. A Reliable Automated Sampling System for On-Line and Real-Time Monitoring of CHO Cultures. Processes 2020, 8, 637. [CrossRef]

134. Jiang, C.; Wang, G.; Hein, R.; Liu, N.; Luo, X.; Davis, J.J. Antifouling Strategies for Selective In Vitro and In Vivo Sensing. Chem. Rev. 2020, 120, 3852-3889. [CrossRef]

135. Wang, D.; Loo, J.F.; Chen, J.; Yam, Y.; Chen, S.-C.; He, H.; Kong, S.K.; Ho, H.P. Recent Advances in Surface Plasmon Resonance Imaging Sensors. Sensors 2019, 19, 1266. [CrossRef]

136. Bravman, T.; Bronner, V.; Nahshol, O.; Schreiber, G. The ProteOn XPR36 ${ }^{\mathrm{TM}}$ Array System—High Throughput Kinetic Binding Analysis of Biomolecular Interactions. Cell. Mol. Bioeng. 2008, 1, 216. [CrossRef]

137. Yang, D.; Singh, A.; Wu, H.; Kroe-Barrett, R. Determination of High-affinity Antibody-antigen Binding Kinetics Using Four Biosensor Platforms. J. Vis. Exp. 2017, 55659. [CrossRef] 
138. Kamat, V.; Rafique, A. Exploring sensitivity \& throughput of a parallel flow SPRi biosensor for characterization of antibodyantigen interaction. Anal. Biochem. 2017, 525, 8-22. [CrossRef] [PubMed]

139. Carterra. Speeding Antibody Screening for Drug Development. Available online: https://www.nature.com/articles/d42473-020 -00177-x (accessed on 16 September 2021).

140. Zeni, L.; Perri, C.; Cennamo, N.; Arcadio, F.; D’Agostino, G.; Salmona, M.; Beeg, M.; Gobbi, M. A portable optical-fibre-based surface plasmon resonance biosensor for the detection of therapeutic antibodies in human serum. Sci. Rep. 2020, 10, 11154 [CrossRef] [PubMed]

141. Liu, Y.; Liu, Q.; Chen, S.; Cheng, F.; Wang, H.; Peng, W. Surface Plasmon Resonance Biosensor Based on Smart Phone Platforms. Sci. Rep. 2015, 5, 12864. [CrossRef] [PubMed]

142. Lertvachirapaiboon, C.; Baba, A.; Shinbo, K.; Kato, K. A smartphone-based surface plasmon resonance platform. Anal. Methods 2018, 10, 4732-4740. [CrossRef]

143. Wong, C.L.; Chua, M.; Mittman, H.; Choo, L.X.; Lim, H.Q.; Olivo, M. A Phase-Intensity Surface Plasmon Resonance Biosensor for Avian Influenza A (H5N1) Detection. Sensors 2017, 17, 2363. [CrossRef]

144. Huang, Y.H.; Ho, H.P.; Wu, S.Y.; Kong, S.K. Detecting Phase Shifts in Surface Plasmon Resonance: A Review. Adv. Opt. Technol. 2012, 2012, 471957. [CrossRef]

145. Kuncova-Kallio, J.; Järvinen, A. Comparison of MP-SPR NaviTM Instruments to Biacore ${ }^{T M}$ in Protein Research; WP_601.809.rg; BioNavis: Tampere, Finland, 2018.

146. Kari, O.K.; Rojalin, T.; Salmaso, S.; Barattin, M.; Jarva, H.; Meri, S.; Yliperttula, M.; Viitala, T.; Urtti, A. Multi-parametric surface plasmon resonance platform for studying liposome-serum interactions and protein corona formation. Drug Deliv. Transl. Res. 2017, 7, 228-240. [CrossRef]

147. Viitala, T.; Granqvist, N.; Hallila, S.; Raviña, M.; Yliperttula, M. Elucidating the signal responses of multi-parametric surface plasmon resonance living cell sensing: A comparison between optical modeling and drug-MDCKII cell interaction measurements. PLoS ONE 2013, 8, e72192. [CrossRef]

148. Suutari, T.; Silen, T.; Karaman, D.S.E.; Saari, H.; Desai, D.; Kerkelä, E.; Laitinen, S.; Hanzlikova, M.; Rosenholm, J.M.; Yliperttula, M.; et al. Real-Time Label-Free Monitoring of Nanoparticle Cell Uptake. Small 2016, 12, 6289-6300. [CrossRef] [PubMed]

149. Koponen, A.; Kerkelä, E.; Rojalin, T.; Lázaro-Ibáñez, E.; Suutari, T.; Saari, H.O.; Siljander, P.; Yliperttula, M.; Laitinen, S.; Viitala, T. Label-free characterization and real-time monitoring of cell uptake of extracellular vesicles. Biosens. Bioelectron. 2020, 168, 112510. [CrossRef] [PubMed]

150. Chabot, V.; Miron, Y.; Grandbois, M.; Charette, P.G. Long range surface plasmon resonance for increased sensitivity in living cell biosensing through greater probing depth. Sens. Actuators B Chem. 2012, 174, 94-101. [CrossRef]

151. Vala, M.; Robelek, R.; Bocková, M.; Wegener, J.; Homola, J. Real-time label-free monitoring of the cellular response to osmotic stress using conventional and long-range surface plasmons. Biosens. Bioelectron. 2013, 40, 417-421. [CrossRef] [PubMed]

152. Vala, M.; Etheridge, S.; Roach, J.A.; Homola, J. Long-range surface plasmons for sensitive detection of bacterial analytes. Sens. Actuators B Chem. 2009, 139, 59-63. [CrossRef]

153. Jing, J.-Y.; Wang, Q.; Zhao, W.-M.; Wang, B.-T. Long-range surface plasmon resonance and its sensing applications: A review. Opt. Lasers Eng. 2019, 112, 103-118. [CrossRef]

154. Yanase, Y.; Yoshizaki, K.; Kimura, K.; Kawaguchi, T.; Hide, M.; Uno, S. Development of SPR Imaging-Impedance Sensor for Multi-Parametric Living Cell Analysis. Sensors 2019, 19, 2067. [CrossRef]

155. Ogura, T.; Tanaka, Y.; Toyoda, H. Whole cell-based surface plasmon resonance measurement to assess binding of anti-TNF agents to transmembrane target. Anal. Biochem. 2016, 508, 73-77. [CrossRef]

156. Abali, F.; Stevens, M.; Tibbe, A.G.J.; Terstappen, L.; van der Velde, P.N.; Schasfoort, R.B.M. Isolation of single cells for protein therapeutics using microwell selection and Surface Plasmon Resonance imaging. Anal. Biochem. 2017, 531, 45-47. [CrossRef]

157. Schasfoort, R.B.M.; Abali, F.; Stojanovic, I.; Vidarsson, G.; Terstappen, L. Trends in SPR Cytometry: Advances in Label-Free Detection of Cell Parameters. Biosensors 2018, 8, 102. [CrossRef]

158. Karlsson, R.; Pol, E.; Frostell, Å. Comparison of surface plasmon resonance binding curves for characterization of protein interactions and analysis of screening data. Anal. Biochem. 2016, 502, 53-63. [CrossRef] [PubMed]

159. Tharmalingam, T.; Wu, C.H.; Callahan, S.; Goudar, T.G. A framework for real-time glycosylation monitoring (RT-GM) in mammalian cell culture. Biotechnol. Bioeng. 2015, 112, 1146-1154. [CrossRef]

160. Mou, Z.-L.; Qi, X.-N.; Liu, R.-L.; Zhang, J.; Zhang, Z.-Q. Three-dimensional cell bioreactor coupled with high performance liquid chromatography-mass spectrometry for the affinity screening of bioactive components from herb medicine. J. Chromatogr. A 2012, 1243, 33-38. [CrossRef] [PubMed]

161. Li, M.-Y.; Ebel, B.; Paris, C.; Chauchard, F.; Guedon, E.; Marc, A. Real-time monitoring of antibody glycosylation site occupancy by in situ Raman spectroscopy during bioreactor CHO cell cultures. Biotechnol. Prog. 2018, 34, 486-493. [CrossRef] [PubMed] 